\title{
Improving Opportunities for Small Flock Egg Production and Proper Evaluation of Glucanase for Commercial Poultry
}

\author{
Angela Elsie Lamp \\ West Virginia University
}

Follow this and additional works at: https://researchrepository.wvu.edu/etd

\section{Recommended Citation}

Lamp, Angela Elsie, "Improving Opportunities for Small Flock Egg Production and Proper Evaluation of Glucanase for Commercial Poultry" (2013). Graduate Theses, Dissertations, and Problem Reports. 346. https://researchrepository.wvu.edu/etd/346

This Thesis is protected by copyright and/or related rights. It has been brought to you by the The Research Repository @ WVU with permission from the rights-holder(s). You are free to use this Thesis in any way that is permitted by the copyright and related rights legislation that applies to your use. For other uses you must obtain permission from the rights-holder(s) directly, unless additional rights are indicated by a Creative Commons license in the record and/ or on the work itself. This Thesis has been accepted for inclusion in WVU Graduate Theses, Dissertations, and Problem Reports collection by an authorized administrator of The Research Repository @ WVU. For more information, please contact researchrepository@mail.wvu.edu. 


\title{
Improving Opportunities for Small Flock Egg Production and Proper Evaluation of Glucanase for Commercial Poultry
}

\author{
Angela Elsie Lamp \\ Thesis submitted to the Davis College of Agriculture, Natural Resources, and Design at \\ West Virginia University \\ in partial fulfillment of the requirements for the degree of \\ Master of Science in Nutrition and Food Science \\ Joseph S. Moritz, Ph.D., Chair \\ Janet C. Tou, Ph.D. \\ Jacek Jaczynski, Ph.D. \\ Department of Division of Animal and Nutritional Sciences
}

Morgantown, West Virginia

2013

Keywords: Marine Oil, EPA, DHA, ALA, Pasture, $\beta$-glucanase, gut viscosity

Copyright 2013 Angela E. Lamp 


\section{ABSTRACT \\ Improving Opportunities for Small Flock Egg Production and Proper Evaluation of Glucanase for Commercial Poultry}

\section{Angela Elsie Lamp}

Consumers of pastured hen eggs have justified paying an associated premium price because they perceive animal welfare, sustainability, and nutrition are enhanced compared to conventionally produced eggs. The objective of Study 1 (Chapter 2) was to implement practical management strategies to increase eicosapentaenoic acid (EPA) and docosahexaenoic acid (DHA) composition of eggs (Experiment 1) and to determine if the same diet formulation would produce an enhanced EPA and DHA egg composition and effect hen health when pasture access and hen breed varied (Experiment 2). For Experiment 1, four dietary treatments were utilized: 1) Basal, 2) Basal + 0.5\% Sardine Oil, 3) Basal + 1\% Marine Oil, and 4) Basal + 1\% Flaxseed Oil. Hens fed Basal $+1 \%$ Sardine Oil produced eggs with the greatest concentration of EPA and DHA (approximately 200mg per egg). Aroma and flavor attributes determined by a taste panel did not demonstrate a dislike for pastured or EPA/DHA eggs. Experiment 2 utilized a split-plot design with housing as the whole plot unit (pasture or conventional without pasture) and a factorial arrangement of treatments applied to subplot pens (2 Breed (124 Single-Comb-White Leghorn SCWL or 124 Red Star (RS)) X 2 Diet (1\% Sardine Oil (Sardine) or 1\% soybean oil (Basal)). Egg EPA content was affected by a House X Diet interaction, demonstrating that hens fed Sardine had elevated EPA; however, the increase was greater when hens were conventionally housed without pasture. Egg DHA content was affected by Diet, showing increased DHA when hens were fed Sardine compared to Basal. These data show that egg EPA and DHA content can be influenced by both diet and housing system as defined by pasture access. In Study 2 (Chapter 3), barley based diets were fed to Cobb x Cobb 500 broilers. Dietary treatments varied in glucanase doses (125 - 2000U/kg of feed), glucanase enzyme type (GA and GB), and degree of processing (unprocessed mash and ground pellet). Inclusion of GA decreased gut viscosity (GV) and increased weight gain for ground pelleted diets, but not unprocessed mash diets. For ground pellets, GA dosed at $1000 \mathrm{U} / \mathrm{kg}$ of feed was superior to the negative control $(150 \mathrm{kcal} / \mathrm{kg}$ energy decrease) and indistinguishable from the positive control for ending bird weight and weight gain. These benefits were not observed for GB, perhaps in part due to a 50\% decrease in activity post pelleting. Evaluations of glucanase should go beyond in vitro activity and include live bird performance using feed that has undergone pelleting. 


\section{ACKNOWLEDGMENTS}

I would first like to thank my advisor and major professor Dr. Joe Moritz for his guidance and support throughout my undergraduate and graduate career. I also want to thank him for all the amazing opportunities and mentorship he has provided to me. I would like to thank my committee members, Drs. Janet Tou and Jacek Jaczynski. Dr. Tou and her lab group assisted me in running blood samples for my laying hen study; she has also been a great role model for me.

Dr. Jaczynski has been an integral member of my committee due to the direction he has provided me. Next, I would like to thank Rick Wood for all his technical support. Without Rick's help my studies would have not gone as smoothly as they did. I would also like to thank the past and present members of Dr. Moritz's Lab Group: Kelley Wamsley, Alina Corey, Ashley Evans, Amanda Brink, John Boney, Mark Lemons and Kevin Shipe. I really appreciate all of your help to complete my studies; as we all know it is very strenuous work. Lastly, I would like to thank my family: Virginia Lamp, Mark Lamp, and Melissa Lamp, my mother’s fiancé Mike Heilman, and my grandparents: Arland and Ruth Ann Lamp and Richard and Theresa Mankowski. Without all of your support and guidance I would not have been able to accomplish all I have today. 


\section{TABLE OF CONTENTS}

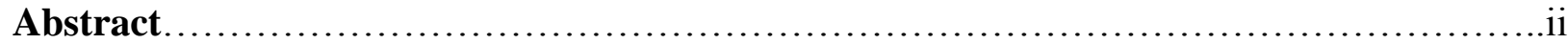

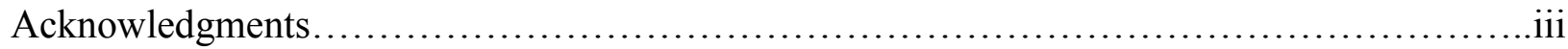

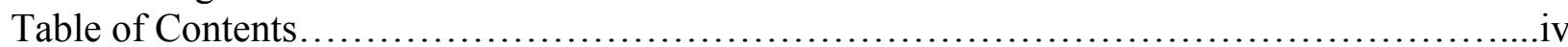

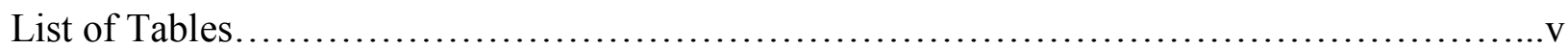

Key ................................................................................

CHAPTER 1: LITERATURE REVIEW..............................................

Small Scale Poultry Production Philosophy........................................... 1

$\Omega-3$ Polyunsaturated Fatty Acids ..................................................... $1-6$

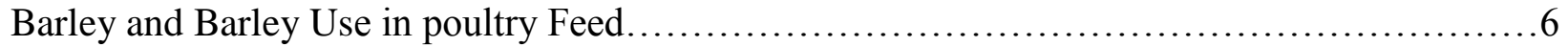

B-Glucanase Enzyme Supplementation.................................................6

Enzyme Supplementation, Feed Manufacture, and Thermal Processing ...................... 7-8

References....................................................................... $8-15$

CHAPTER 2: The effect of pasture access, breed, and diet on laying hen health, performance, consumer acceptability of eggs, and EPA and DHA content of eggs..........................16

Summary........................................................................ 17-18

Description of the Problem............................................................... 19

Materials and Methods...............................................................20-23

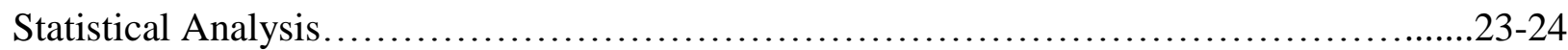

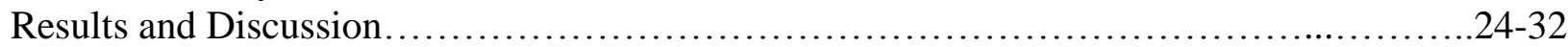

Conclusions and Applications......................................................... 32

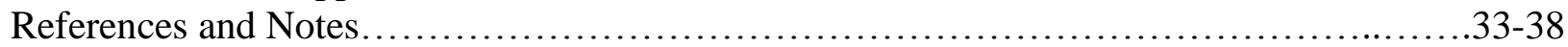

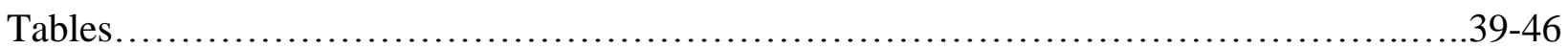

CHAPTER 3: The effects of pelleting and glucanase supplementation in barley based diets on feed manufacture, broiler performance, and gut viscosity...............................47

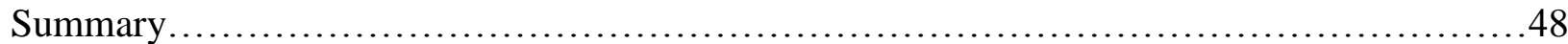

Description of the Problem........................................................ $48-50$

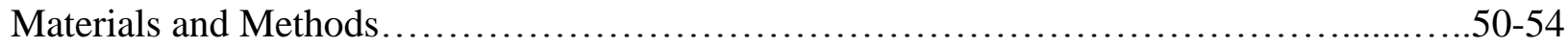

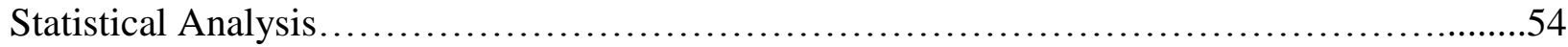

Results and Discussion..................................................................... 57

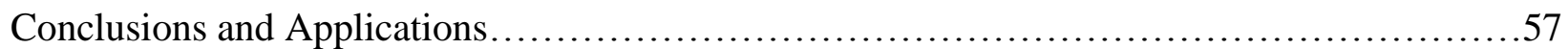

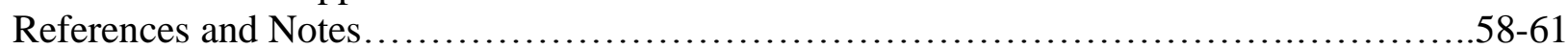

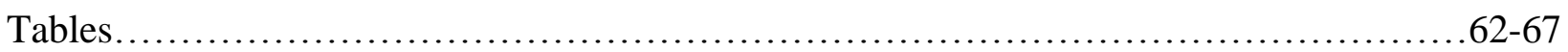

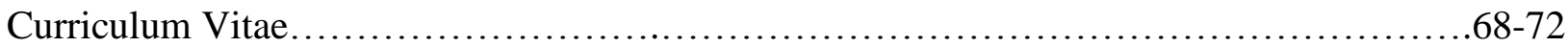




\section{LIST OF TABLES}

\section{CHAPTER 2}

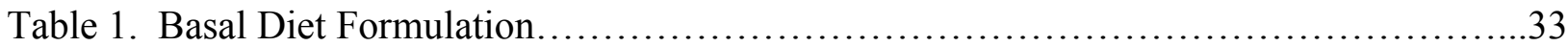

Table 2. Effects of oil inclusion on laying hen performance data (Experiment 1)................34

Table 3. Fatty acid content found performing a fatty acid analysis on eggs collected in this

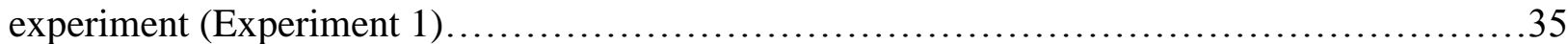

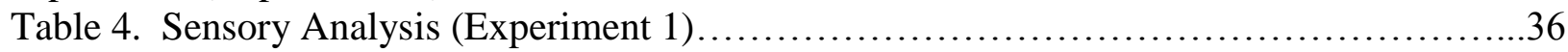

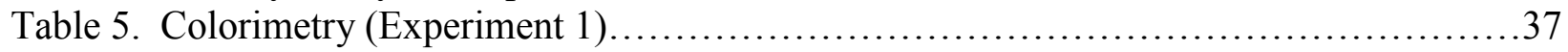

Table 6. Effects of housing environment, breed, and diet on laying hen performance

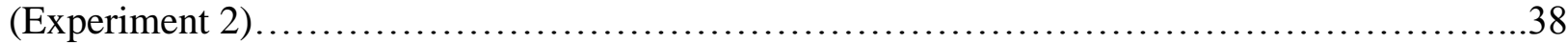

Table 7. Effects of housing environment, breed, and diet on fatty acid content of eggs collected

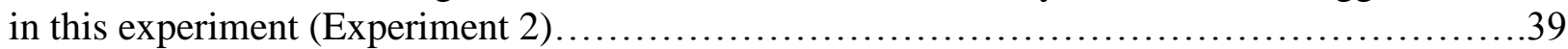

Table 8 . Effects of housing environment, breed, and diet on serum chemistry

(Experiment 2)

\section{CHAPTER 3}

Table 1. Diet formulations for the negative and positive control diets .55

Table 2. Feed manufacture variables associated with variation in diet formulation (descriptive data).

Table 3. The effect of Glucanase A dose $(0,125,1000)$ and processing (unprocessed mash or ground pellet) on broiler performance and gut viscosity

Table 4. The effect of diet formulation (NC, PC, Glucanase A $1000 \mathrm{U} / \mathrm{kg}$ feed, Glucanase B $1000 \mathrm{U} / \mathrm{kg}$ feed) and processing (unprocessed mash or ground pellet) on broiler performance and gut

viscosity.

Table 5. Overall comparison of all dietary treatments on broiler performance and digesta viscosity 


\section{CHAPTER 1}

1. Polyunsaturated Fatty Acids PUFAs

2. Eicosapentaenoic Acid - EPA

3. Docosahexaenoic Acid - DHA

4. Alpha-linolenic Acid - ALA

5. National Health and Nutrition Examination Survey - NHANES

6. Nonstarch Polysaccharide - NSP

\section{CHAPTER 2}

1. Eicosapentaenoic Acid - EPA

2. Docosahexaenoic Acid - DHA

3. Hy-line W-36 Single-Comb-White Leghorn Hen - SCWL

4. Red Star Hen - RS

5. Alpha-linolenic Acid - ALA

6. Feed Intake - FI

7. Feed Conversion Ratio - FCR

8. Alkaline Phosphatase - ALP

9. Gamma-glutamyl Transpeptidase GGT

10. Phosphorous - PHOS

11. Albumin - ALB

12. Uric Acid - URIC

13. Aspartate Aminotransferase - AST

14. Alanine Aminotransferase - ALT

15. Glucose - Gluc

16. Cholesterol - Cholest

17. Total Protein - TRPO

18. Amylase - AMY

19. Urea Nitrogen - BUN

20. Creatine Kinase - CK

21. Albumin/Globulin Ration -
ALB/GLOB

22. Globulins - GLOB

23. Urea Nitrogen/Creatinine Ration BUN/CREA

24. 1\% Sardine Oil - Sardine

25. 1\% Soybean Oil - Basal

\section{CHAPTER 3}

1. Glucanase-Gluc

2. Digesta Viscosity - DV

3. Glucanase $\mathrm{A}-\mathrm{GA}$

4. Glucanase $\mathrm{B}-\mathrm{GB}$

5. Feed Intake - FI

6. Live Weight Gain - LWG

7. Positive Control - PC

8. Negative Control - NC

9. Hot Pellet Temperature - HPT

10. Pellet Durability Index - PDI

11. Dinitrosalicyclic Acid - DNS

12. Feed Conversion Ration - FCR 


\section{CHAPTER 1: LITERATURE REVIEW}

\section{SMALL SCALE POULTRY PRODUCTION PHILOSOPHY}

Small scale, pastured egg production requires increased labor, land, and feed resources, thus a premium price must be obtained for eggs from these producers. Consumers justify spending more for these eggs because they perceive animal welfare and nutrition are enhanced compared to conventionally produced eggs [1]. Small scale egg producers would undoubtedly benefit from use of production strategies that alter the nutritional quality of pasture eggs relative to most conventionally produced eggs.

\section{2. $\Omega-3$ POLYUNSATURATED FATTY ACIDS}

The $\omega-3$ fatty acids are essential for normal growth and development and may play an important role in the prevention and treatment of human coronary artery disease, hypertension, diabetes, arthritis, other inflammatory and autoimmune disorders, and cancer [2 - 7]. Fatty acids typically have an even number of carbon atoms, in the range of 16-26. Fatty acids with only single bonds between adjacent carbon atoms are referred to as "saturated"; whereas, those with at least one carbon, carbon double bond are called "unsaturated". The polyunsaturated fatty acids (PUFAs) have two or more double bonds, and they are named according to the position of these bonds and the total chain length [8]. The term " $\omega$-3" indicates that, counting from the methyl $\left(\mathrm{CH}_{3}\right)$ end of the molecule, the first double bond is located between the third and fourth carbons. As the degree of unsaturation in fatty acids increases, the melting point decreases [8]. The major $\omega-3$ PUFAs important in human health include the essential fatty acids EPA, DHA, and ALA [8]. Alpha-linolenic acid (ALA) is the 18-carbon, 3-double bond (C18:3 $\omega$-3) precursor to eicosapentaenoic acid (EPA) and docosahexaenoic acid (DHA), the latter 2 being the 
predominant $\omega-3$ fatty acids in fish oils. Alpha-linolenic acid is found in certain plant oils, most notably flaxseed oil (where it constitutes $\sim 50 \%$ of total fatty acids) and in canola oil ( $\sim 9 \%)$, unhydrogenated soybean (salad dressing) oil ( $\sim 7 \%)$, hydrogenated soybean oil $(\sim 3 \%)$, and olive oil ( 1\%). According to National Health and Nutrition Examination Survey (NHANES) III data, consumption in the United States currently averages $\sim 1.3 \mathrm{~g} / \mathrm{d}$ [9].

Synthesis of DHA and EPA occurs in phytoplankton and animals, but not plants. Docosahexaenoic acid and EPA are absent from all vegetable fats and oils, including nuts, grains, and seeds. These fatty acids are also very low in ruminant fats, including milk and dairy products [10]. The richest dietary sources are fish and sea foods; and poultry and eggs provide lower, but important, sources of EPA and DHA [11]. Also, DHA is the most abundant $\omega-3$ fatty acid in the mammalian brain. Docosahexaenoic acid levels in the brain membrane lipids increase with development and decrease with aging [12, 13, 14]. Mammals obtain DHA either as DHA itself or the precursor ALA [10].

The major $\omega$-3 PUFAs important in human health include the essential fatty acids, ALA

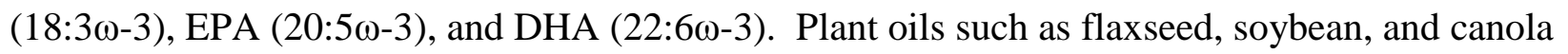
are rich sources of ALA [15], while marine oils have substantial levels of both EPA and DHA [11]. All three PUFAs have distinct biological effects. In human nutrition, ALA is needed in the diet in order to synthesize longer chain PUFAs such as EPA and DHA [15]. However, the conversion efficiency of ALA to EPA and DHA is, at best, 5\% in men and slightly higher in women [16]. Eicosapentaenoic acid and DHA are converted to eicosanoids and docosanoids which play an important role in regulating many biological functions: blood pressure, platelet aggregation, blood clotting, blood lipid profiles, and immune and inflammation responses during injury [17]. 


\section{Health Benefits}

Consumption of the $\omega-3$ PUFAs ALA, EPA, and DHA can provide health benefits such as improvement of cognitive function, decrease in inflammatory joint pain, and improvement of the cardiovascular system [8]. A large number of clinical trials have been conducted on the effects of DHA supplementation in infants fed formula; these findings have had varied results.

Regardless of the absence of differences between placebo and DHA intervention groups, a positive association between the infants' DHA status and neurodevelopmental outcome has been shown in several studies $[18,19,20]$. Some longer-term follow-up studies are also emerging to suggest positive effects of early enhanced DHA nutrition on mental and motor skill development when measured in early childhood $[21,22]$. However, some scientists find no advantage of enhanced DHA nutrition on mental and motor skill development in infants $[23,24]$. Recently, attention has turned to DHA supplementation of pregnant and lactating women, again with most studies reporting no advantages to infant development during the first year after birth [18, 19, 20, $24,25,26]$.

Consuming $\omega$-3 PUFAs can also decrease inflammatory joint pain. Excessive or inappropriate inflammation contributes to a range of acute and chronic human diseases and is characterized by the production of inflammatory cytokines, arachidonic acid- derived eicosanoids (prostaglandins, thromboxanes, leukotrienes, and other oxidized derivatives), other inflammatory agents (eg, reactive oxygen species), and adhesion molecules. At sufficiently high intakes, long-chain $\omega$-3 PUFAs decrease the production of inflammatory eicosanoids, cytokines, and reactive oxygen species and the expression of adhesion molecules [27]. Long-chain $\omega-3$ PUFAs act directly by replacing arachidonic acid as an eicosanoid substrate and inhibiting arachidonic acid metabolism. Polyunsaturated fatty acids also act indirectly by altering the 
expression of inflammatory genes through effects on transcription factor activation. Evidence of their clinical efficacy is reasonably strong in rheumatoid arthritis; but, it is weak in inflammatory bowel diseases and asthma. More, better designed, and larger trials are required to assess the therapeutic potential of $\omega-3$ PUFAs in inflammatory diseases [27].

A third health benefit to adding $\omega$-3 PUFAs to the diet is that it improves the cardiovascular system. Bucher and others [28] conducted a meta-analysis of 11 randomizedcontrolled trials which involved a total of 7,951 patients in the intervention groups and employed supplementation levels of 0.3-6.0 $\mathrm{g} \mathrm{day}^{-1}$ for EPA, and 0.6-3.7 $\mathrm{g} \mathrm{day}^{-1}$ for DHA. The metaanalysis concluded that $\omega-3$ PUFAs could reduce overall mortality, mortality because of myocardial infarction and sudden death in patients with coronary heart disease [28]. The GISSI Intervenzione study [29] is the largest $\omega-3$ trial conducted involving 11,324 subjects who had survived an acute myocardium infraction. Subjects, who were followed for 3.5 years, were assigned to one of four groups: 1) $0.88 \mathrm{~g} \mathrm{day}^{-1}$ omea-3 PUFA (1:2, EPA:DHA) alone; 2) $\omega-3$ PUFA + 300 mg day ${ }^{-1}$ vitamin E; 3) vitamin E alone; 4) no treatment. The subjects given $\omega-3$ PUFA showed a significant reduction in cardiac events. Inclusion of vitamin E offered no additional protection [29].

The incorporation of these oils (marine and soybean) into laying hen diets and the subsequent deposition into eggs may better justify egg premiums due to these fatty acids being associated with a plethora of health benefits [2-7]. Past research has indicated a consumer driven market for the increased production of functional foods [30, 31] and surveys have demonstrated that consumers have a growing interest surrounding the production of $\omega-3$ enriched foods as dietary alternatives to the consumption of fish [32]. 


\section{Functional Food}

The incorporation of marine and soybean oil into laying hen diets and the subsequent deposition into eggs may better justify egg premiums due to these fatty acids being associated with a multitude of health benefits. The concept of healthy food additives has come from Japan in the 1970's with the term "functional foods" appearing in 1984 [33]. The Food and Nutrition Board of the National Academy of Sciences defines a functional food as one that encompasses potentially healthy products providing health benefit beyond that of traditional nutrients it contains [34]. This is in agreement with data from the recent USA study from written questionnaires completed by 2,074 qualified respondents in 1998 indicating that most shoppers believe foods can offer benefits that reach beyond basic nutrition to functional nutrition for disease prevention and health enhancement [32]. Today, functional foods receive extensive attention $[30,31]$ and represent one of the fastest growing divisions of the world food industry [33]. For example, dairy products and other processed foods, including mayonnaise, margarine, dressings containing DHA [35] as well as $\omega-3$ enriched eggs [36, 37] are already on the market in different countries. In the USA, annual sales of functional food products comprise around $\$ 50$ billion [33].

Commercial table eggs contain a high proportion of $\omega-6$ PUFA (mainly 18:2 $\omega-6$ ) but are a poor source of $\omega-3$ fatty acids. Attempts to produce eggs high in $\omega-3$ PUFAs can be divided into two groups. 1) The simplest way is to produce an egg enriched in ALA [36], which is a precursor of DHA and is also considered to have a protective effect against fatal ischemic heart disease $[38,39]$. To incorporate this ALA into the hen's diet flaxseeds, linseeds or their corresponding oils are usually added; as a result the egg's yolk is enriched with ALA and the level of DHA is also enhanced [40]. 2) The second route to enhancing levels of $\omega-3$ in the egg is 
by including pre-formed DHA in the hen's diet, usually in the form of fish (menhaden, herring or tuna) oil [37]. However, this may be associated with a pronounced fishy taste in the egg yolk.

\section{BARLEY AND BARLEY USE IN POUTRY FEED}

Barley use in poultry diets has been traditionally restricted in the United States due to its low energy value and subsequent sticky droppings, impairment of broiler performance, and decrease of digestion and absorption of nutrients [41 - 44]. However, today barley is being used more frequently as a feed component because of the better knowledge of its chemical composition and the remarkable progress in biotechnological production of commercial enzymes $[45,46]$

The mixed linked 1, 3:1, 4- $\beta$-glucans are considered the source of all the detrimental effects barley causes poultry $[41,43,44]$. The nonstarch polysaccharide (NSP) portion of barley protects starch, protein, and lipids; therefore, making it challenging for digestive enzymes to reach these components [47].

\section{4. $\beta$-GLUCANASE ENZYME SUPPLEMENTATION}

The addition of a glucanase enzyme to a barley based broiler diet can provide several benefits. The enzyme can improve the efficiency of feed utilization, contribute to a better use of low cost feed ingredients [48, 49], reduce sticky droppings [41] and intestinal viscosity [50 - 52], and improve digestion and absorption of starch, protein, and fat [53, 54]. These factors all lead to increased broiler productivity $[44,53,55]$. 


\section{ENZYME SUPPLMENTATION, FEED MANUFACTURE, AND THERMAL PROCESSING}

Enzymatic structure is very critical when it comes to the activity of a certain enzyme. An enzyme can undergo denaturation when it is exposed to heat, certain organic solvents, or extremes of $\mathrm{pH}[56]$.

Pelleting and glucanase supplementation are common practices utilized prior to feeding broilers barley based diets; however, the interaction of these practices is complex. Thermal stability throughout the pelleting process is a major concern for any mixer-added enzyme [57, 58]. It has been proposed that most inactivation of mixer-added enzymes take place during conditioning, when the feed is heated with saturated steam, rather than during extrusion of feed through the pellet die [59]. However, some studies have proposed mixer-added enzyme inactivation to be associated with frictional heat and pressure in the pellet die $[56,60]$.

Thermal processing and glucanase supplementation have been shown to have opposing effects on GV; and if glucanase is added at the mixer, then glucanase thermal stability becomes a concern. Past research has varied in methods and results on testing the thermal stability of $\beta$ glucanase. Inborr and Bedford [61] tested $\beta$-glucanase activity in feed and found that conditioning the feed at $85^{\circ} \mathrm{C}$ did not reduce enzyme activity compared to $75^{\circ} \mathrm{C}$; however, $95^{\circ} \mathrm{C}$ conditioning caused significant inactivation. Esteve-Garcia and others [57] tested the effects of pelleting diets supplemented with $\beta$-glucanase at temperatures around $80^{\circ} \mathrm{C}$ and found that the enzymes maintained over $80 \%$ of their activity. Conversely, Almirall and others [62] incubated $\beta$-glucanase in solution at $70^{\circ} \mathrm{C}, 80^{\circ} \mathrm{C}$, and $100^{\circ} \mathrm{C}$ and found that activity was reduced to 65,20 , and $0 \%$ respectively [57]. Viveros and others [63] autoclaved $\beta$-glucanase at 50,70 , and $90^{\circ} \mathrm{C}$ 
and due to the increase of growth in the birds fed diets containing enzyme, no inactivated took place.

\section{REFERENCES}

1. Tactacan, G. B., W. Guenter, N. J. Lewis, J. C. Rodriguez-Lecompte and J. D. House. 2009. Performance and welfare of laying hens in conventional and enriched cages. Poult. Sci. $88: 698-707$.

2. Simopoulos, A. P., R. R. Kifer, and R. E. Martin, ed., 1986. Health Effects of Polyunsaturated Fatty Acids in Seafoods. Academic Press, Orlando, FL.

3. Galli, C., and A. P. Simopoulos, 1989. Dietary $\omega-3$ and $\omega-6$ fatty acids: Biological effects and nutritional essentiality. Plenum Press, New York, NY.

4. Simopoulos, A. P., R. R. Kifer, R. E. Martin, and S. M. Barlow, 1991. Health effects of $\omega 3$ polyunsaturated fatty acids in seafoods. World Rev. Nutr. Diet. 66:1-592.

5. Galli, C., A. P. Simopoulos, and E. Tremoli, ed., 1994a. Fatty acids and lipids: Biological aspects. World Rev. Nutr. Diet. 75:1-197.

6. Galli, C., A. P. Simopoulos, and E. Tremoli, ed., 1994b. Effects of fatty acids in health and disease. World Rev. Nutr. Diet. 76:1-152.

7. Salem, N., Jr., A. P. Simopoulos, C. Galli, M. Lagarde, and H. R. Knapp, ed., 1996. Fatty Acids and Lipids from Cell Biology to Human Disease. Lipids 31(Suppl):S1-S326.

8. Ruxton, C. H. S., S. C. Reed, M. J. A. Simpson, K.J. Millington. 2004. The health benefits of omega-3 polyunsaturated fatty acids: a review of the evidence. J. Hum. Nutr. Dietet, 17, pp 449-459.

9. Harris, W. S. 2005. Alpha-Linolenic Acid: A Gift From the land? Circulation 111: 28722874. 
10. Innis, S. M. 2007. Dietary (n-3) Fatty Acids and Brain Development. American Society for Nutrition. J. Nutr. 137:855-859.

11. Innis, S. M. 2003. Perinatal biochemistry and physiology of long chain polyunsaturated fatty acids. J Pediatr. 143:S1-8.

12. Innis, S. M. 2005. Essential fatty acid metabolism during early development. In: Biology of Metabolism in Growing Animals. Burrin DG ed. Pub. Elsevier Science, B.V. Amsterdam, Part III, pp. 235-74.

13. Guisto, N. M., G. A. Salvador, P. I. Castagnet, S. J. PAsquare, M. G. Ilincheta de Bschero. 2002. Age-associated changes in central nervous system glycerophospholipids composition and metabolism. Neurochem Res. 27:1513-23.

14. Uauy R., A. D. Dangour. 2006. Nutrition in brain development and aging: role of essential fatty acids. Nutr Rev. 64:S24-33.

15. Harris, W. S. 2005. Alpha-Linolenic Acid: A Gift From the land? Circulation 111: 28722874.

16. Gerster, H. 1998. Can adults convert a-linolenic acid (18:3n-3) to eicosapentaenoic acid (20:5n-3) and docosahexaenoic acid (22:5n-3)? International Journal of Vitamin and Nutrition Research 68, 159-173.

17. Ratnayake, W. M. N, C. Galli. 2009. Fat and fatty acid terminology, methods of analysis and fat digestion and metabolism: a background review paper. Ann Nutr Metab; 55:8-43.

18. Malcolm, C. A., D. L. McCulloch, C. Montgomery, A. Shepherd, L. T. Weaver. 2003. Maternal docosahexaenoic acid supplementation during pregnancy and visual evoked potential development in term infants: a double blind, prospective, randomized trial. Arch Dis Child Fetal Neonat Ed. 88:F383-90. 
19. Lauritzen, L., S. H. Jorgensen, T. B. Mikkelsen, M. Skovgaard, E. M. Straarup, S. F. Olsen, C. F. Hoy, K. F. Michaelsen. 2004. Maternal fish oil supplementation in lactation: effect on infant visual acuity and n-3 fatty acid content in infant erythrocytes. Lipids. 39:195-206.

20. Helland, I. B., O. D. Saugstad, L. Smith, K. Saarem, K. Solvoll, T. Ganes, C. A. Drevon. 2001. Similar effects on infants of n-3 and n-6 fatty acids supplementation to pregnant and lactating women. Pediatrics. 108:E82.

21. Helland, I. B., L. Smith, K. Saarem, O. D. Saugsad, C. A. Drevon. 2003. Maternal supplementation with very-long-chain-n-3 fatty acids during pregnancy and lactation augments children's IQ at 4 years of age. Pediatrics. 111:E39-44.

22. Jensen, C. L., R. G. Voigt, T. C. Prager, Y. L. Zou, J. K. Fraley, J. C. Rozelle, et al. 2005. Effects of maternal docosahexaenoic acid intake on visual function or neurodevelopment in breastfed term infants. Am J Clin Nutr. 82:125-32.

23. Heird, W. C., A. Lapillone. 2005. The role of fatty acids in development. Annu Rev Nutr. 25:549-71.

24. Fewtrell, M. S. 2006. Long-chain polyunsaturated fatty acids in early life: effects on multiple health outcomes. A critical review of current status, gaps and knowledge. Nestle Nutr Workshop Ser Pediatr Program. 57:203-14.

25. Lauritzen, L., S. H. Jorgensen, S. E. Olsen, E. M. Straarup, T. B. Mikkelsen. 2005. Maternal fish oil supplementation in lactation: effect on developmental outcome in breast-fed infants. Reprod Nutr Dev. 45:535-47. 
26. Tofail F., I. Kabir, J. D. Hamadani, F. Chowdhury, S. Yesmin, F. Mehreen, S.N. Huda. 2006. Supplementation of fish-oil and soy-oil during pregnancy and psychomotor development of infants. J Health Popul Nutr. 24: 48-56.

27. Calder, P. C. 2006. n-3 polyunsaturated fatty acids, inflammation, and inflammatory diseases. Am. J. Clin. Nutr. 83:1505S-19S.

28. Bucher, H.C., P. Hengstler, C. Schindler, G. Meier. 2002. N-3 polyunsaturated fatty acids in coronary heart disease: a meta-analysis of randomized controlled trials. Am. J. Med. $112,298-304$.

29. GISSI. 1999. Dietary supplementation with n-3 polyunsaturated fatty acids and vitamin E after myocardial infarction: results of the GISSI-Prevenzione trial. Gruppo Italiano per lo Studio della Sopravvivenza nell'Infarto miocardico. Lancet 354, 447-455.

30. Mazza, G. (ed.) 1998. 'Functional Foods. Biochemical \& Processing Aspects', Technomic Publishing Co. Lancaster/Basel.

31. Reilly, C. 1998. SeA New Entrant Into the Functional Food Arena. Trends Food Sci. Technol., 9, pp. 114-118

32. Gilbert, L. C. 2000. The functional food trend What's next and what Americans think about eggs. J. Am. Coll. Nutr. 19 (5 Suppl), 507S-512S.

33. Harris, C. 2000.'Meat products are perfect as functional foods’ in Meat Processing Jan/Feb, 19.

34. Milner, J. A. 2000. Functional FoodsThe US Perspective. Am. J. Clin. Nutr., 71, pp. $1654 \mathrm{~S}-1659 \mathrm{~S}$

35. Takahata, K., K. Monobe, M. Tada, P.C. Weber. 1998. The Benefits and Risks of N-3 Polyunsaturated Fatty Acids. Biosci. Biotech. Biochem., 62, pp. 2079-2085. 
36. Van Elswyk, M. E. 1997. Nutritional and Physiological Effects of Flax Seed in Diets for Laying Fowl. World's Poult. Sci. J., 53, pp. 253-264.

37. Leskanich, C. O., R.C. Noble. 1997. Manipulation of the n-3 Polyunsaturated Fatty Acid Composition of Avian Egg and Meat. World's Poultry Sci. J., 53, pp. 155-183.

38. Hu, F. B., M.J. Stampfer, J.E. Manson, E.B. Rimm, A. Wolk, G.A. Colditz, C.H. Hennekens, W.C. Willett. 1999. Dietary Intake of Alpha-Linolenic Acid and Risk of Fatal Ischemic Heart Disease Among Women. Am. J. Clin. Nutr., 69, pp. 890-897.

39. de Lorgeril, M., S. Renaud, N. Mamelle, P. Salen, J.L. Martin, I. Monjaud, J. Guidollet, P. Touboul, J. Delaye. 1994. Mediterranean Alpha-Linolenic Acid-rich Diet in Secondary Prevention of Coronary Heart Disease. Lancet, 343, pp. 1454-1459.

40. Ferrier, L.K., L.J. Caston, S. Leeson, J. Squires, B.J. Weaver, B.J. Holub. 1995. AlphaLinolenic Acid- and Docosahexaenoic Acid-enriched Eggs from Hens Fed FlaxseedInfluence on Blood Lipids and Platelet Phospholipid Fatty Acids in Humans. Am. J. Clin. Nutr., 62, pp. 81-86.

41. Gohl, B., S. Aldén, K. Elwinger, and S. Thomke. 1978. Influence of $\beta$-glucanase on feeding value of barley for poultry and moisture content of excreta. British Poult. Sci. 19: 41-47.

42. Annison, G. and M. Choct. 1991. Anti-nutritive activities of cereal non-starch polysaccharides in broiler diets and strategies minimizing their effects. World's Poult. Sci. J. 47:232-242.

43. Hesselman, K., K. Elwinger, M. S. Nilson, and S. Thomke. 1981. The effect of $\beta$ glucanase supplementation stages of ripeness and storage treatment of barley in diets fed to broiler chickens. Anim. Feed Sci. Technol. 60:1664-2671. 
44. Rotter, B. A., M. Neskar, R. R. Marquardt, and W. Guenter. 1989. Effects of different enzyme preparations on the nutritional value of barley in chicken diets. Nutr. Rep. Int. 39:107-120.

45. Jeroch, H. and S. Dänicke. 1995. Barley in poultry feeding: a review. World's Poult. Sci. J. 51:271-291.

46. Fuente, J. M., P. Perez de Ayala, A. Flores, and M. J. Villamide. 1998. Effect of storage time and dietary enzyme on the metabolizable energy and digesta viscosity of barleybased diets in poultry. Poult. Sci. 77:90-97.

47. García, M., R. Lázaro, M. A. Latorre, M. I. Gracia, and G. G. Mateos. 2008. Influence of enzyme supplementation and heat processing of barley on digestive traits and productive performance of broilers. Poult. Sci. 87: 940-948.

48. Chesson, A. 1993. Feed enzymes. Anim. Feed Sci. Technol. 45:65-69.

49. Bedford, M. R. 2000. Exogenous enzymes in monogastric nutrition - The current value and future benefits. Anim. Feed Sci. Technol. 86:1-13.

50. Gohl, B. 1977. Influence of water treatment of barley on the digestion process in rats. Department of Animal Husbandry, Agricultural College of Sweden, Uppsala.

51. Hesselman, K. 1983. Effects of $\beta$-glucanase supplementation to barley based diets for broiler chickens. Ph.D. Thesis, Department of Animal Husbandry, Swedish University of Agricultural Science, Uppsala.

52. White, W. B., H. R. Bird, M. L. Sunde, and J. A. Marlett. 1983. Viscosity of $\beta$-glucan as a factor in the enzymatic improvement of barley for chicks. Poult. Sci. 62:853-862. 
53. Hesselman, K. and P. Åman. 1986. The effect of $\beta$-glucanase on the utilization of starch and nitrogen by broiler chickens fed on barkey of low-or-high-viscosity. Anim. Feed Sci. and Technol. 15:83-93.

54. Annison, G. 1992. Commercial enzyme supplementation of wheat-based diets raises ileal glycanase activities and improves apparent metabolisable energy, starch and pentosan digestibilities in broiler chickens. Anim. Feed Sci. and Technol. 38:105-121.

55. Classen, H. L., G. L. Campbell, B. G. Rossnagel, R. Bhatty, and R. D. Reichert. 1985. Studies on the use of hulless barley in chick diets: Deleterious effects and methods of alleviation. Can. J. Anim. Sci. 65:725-733.

56. Spring, P., K. E. Newman, C. Wenk, R. Messikommer, and M. Vukic Vranjes. 1996. Effect of pelleting temperature on the activity of different enzymes. Poult. Sci. 75:357361.

57. Esteve-Garcia, E., J. Brufau, A. Pérez-Vendrell, A. Miquel, and K. Duven. 1997. Bioefficacy of enzyme preparations containing $\beta$ - glucanase and xylanase activities in broiler diets based on barley or wheat, in combination with flavomycin. Poult. Sci. 76:1728-1737.

58. Silversides, F. G., and M. R. Bedford. 1999. Effect of pelleting temperature on the recovery and efficacy of a xylanase enzyme in wheat-based diets. Poult. Sci. 78:11841190.

59. Eeckhout, M., M. DeSchrijver, and E. Vanderbeke. 1995. The influence of process parameters on the stability of feed enzymes during steam pelleting. Pages 163-169 in: Proceedings of the $2^{\text {nd }}$ European Symposium on Feed Enzymes. Noordwijkerhout, The Netherlands. 
60. Gehring, C. K., K. G. S. Lilly, L. K. Shires, K. R. Beaman, S. A. Loop, and J. S. Moritz. 2011. Increasing mixer-added fat reduces the electrical energy required for pelleting and improves exongenous enzyme efficacy for broilers. J. Appl. Poult. Res. 20:75-89.

61. Inborr, J., and M. R. Bedford. 1994. Stability of enzymes to steam pelleting during feed processing. Anim. Feed Sci. and Technol. 46:179-196.

62. Almirall, M., M. Francesch, A. M. Pérez-Vendrell, J. Brufau, and E. Esteve-Garcia. 1995. The differences in intestinal viscosity produced by barley and $\beta$-glucanase alter digesta enzyme activities and ileal nutrient digestibilities more in broiler chicks than in cocks. J. Nutr. 125:947-955.

63. Viveros, A., A. Brenes, M. Pizzarro, M. Castaño. 1994. Effect of enzyme supplementation of a diet based on barley, and autoclave treatment, on apparent digestibility, growth performance and gut morphology of broilers. Anim. Feed Sci. and Technol. 48:237-251. 
CHAPTER 2: The Effect of Pasture Access, Breed, and Diet on Laying Hen Health, Performance, Consumer Acceptability of Eggs, and EPA and DHA Content of Eggs

A.E. Lamp*, M.E. Lemons", K.G.S. Wamsley, A. M. Evans", K. Matak", and J.S. Moritz , *Division of Animal and Nutritional Sciences, West Virginia University, Morgantown 26506

Primary Audience: Nutritionists, Organic Producers, Production Managers, Researchers

${ }^{1}$ Corresponding author: Joe.Moritz@mail.wvu.edu 


\section{SUMMARY}

The objective of this study was to implement practical management strategies to increase eicosapentaenoic acid (EPA) and docosahexaenoic acid (DHA) composition of eggs (Experiment 1) and to determine if the same diet formulation would produce an enhanced EPA and DHA egg composition and effect hen health when pasture access and hen breed varied (Experiment 2). For Experiment 1, 300 Hy-line W-36 Single-Comb-White Leghorn hens (SCWL) were weighed and allocated 15 hens per quadrant of each of five mobile poultry houses that provided pasture access. Four dietary treatments were utilized: 1) Basal, 2) Basal $+0.5 \%$ Sardine Oil, 3) Basal $+1 \%$ Sardine Oil, and 4) Basal $+1 \%$ Flaxseed Oil. Hens fed Basal $+1 \%$ Sardine Oil produced eggs with the greatest concentration of EPA and DHA (approximately $200 \mathrm{mg} / \mathrm{egg}, \mathrm{P}<0.0001)$. Aroma and flavor attributes determined by a taste panel did not indicate aversion to the pastured or EPA/DHA eggs. Experiment 2 utilized the same mobile poultry houses and raised wire conventional hen cages to compare the basal diet and basal $+1 \%$ Sardine diet. This study utilized a split-plot design with housing as the whole plot unit (pasture or conventional without pasture) and a factorial arrangement of treatments applied to subplot pens (2 Breed (124 SCWL or 124 Red Star (RS)) X 2 Diet (1\% Sardine Oil (Sardine) or 1\% soybean oil (Basal)). Egg EPA content was affected by a House X Diet interaction demonstrating that hens fed Sardine had elevated EPA; however, the increase was greater when hens were conventionally housed without pasture $(\mathrm{P}<0.0001)$. Egg DHA content was affected by Diet, showing increased DHA when hens were fed Sardine compared to Basal $(\mathrm{P}<0.0001)$. Aspartate Amino Transferase (AST) activity, was affected by a House X Breed interaction describing that the SCWL had elevated AST activity when housed conventionally without pasture $(<0.0001)$. However, all hens displayed a healthy serum AST activity. These data show 
that egg EPA and DHA content can be influenced by both diet and housing system as defined by pasture access.

Keywords: Sardine Oil, EPA, DHA, pasture access

\section{DESCRIPTION OF PROBLEM}

Small scale, pastured egg production requires increased labor, land, and feed resources, consequently requiring a premium market price. Consumers justify spending more for these eggs because they perceive animal welfare and nutrition are enhanced compared to conventionally produced eggs. These perceptions are often unfounded. Small scale egg producers may benefit from use of production strategies that alter the nutritional quality of pasture eggs relative to most conventionally produced eggs.

The major $\omega-3$ polyunsaturated fatty acids (PUFAs) important in human health include the essential fatty acid, alpha-linolenic acid (ALA, 18:3w-3), eicosapentaenoic acid (EPA,

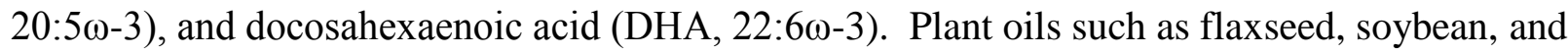
canola are rich sources of ALA, while fish and marine oils have substantial levels of both EPA and DHA [1]. All three PUFAs have distinct biological effects. In human nutrition, ALA is needed in the diet in order to synthesize longer chain PUFAs such as EPA and DHA. However, the conversion efficiency of ALA to EPA and DHA is, at best, 5\% in men and slightly higher in women [2]. Both EPA and DHA are converted to eicosanoids and docosanoids that help regulate many biological functions such as: blood pressure, platelet aggregation, blood clotting, blood lipid profiles, and immune and inflammation responses during injury [3]. Consumption of the $\omega$ 3 PUFAs ALA, EPA, and DHA can provide human health benefits such as improvement of cognitive function, decrease in inflammatory joint pain, and improvement of the cardiovascular 
system. A positive association between infants' DHA status and neurodevelopmental outcome has been shown in several studies $[4,5,6]$. At sufficiently high intakes, long-chain $\omega-3$ PUFAs decrease the production of inflammatory eicosanoids, cytokines, and reactive oxygen species and the expression of adhesion molecules [7]. Polyunsaturated fatty acids also act indirectly by altering the expression of inflammatory genes through effects on transcription factor activation [7]. The GISSI Intervenzione study showed a significant reduction in cardiac events for subjects given $\omega-3$ PUFAs [8].

The incorporation of these fatty acids into laying hen diets and the subsequent deposition into eggs may better justify egg premiums due to the aforementioned functions and associated health benefits. The Food and Nutrition Board of the National Academy of Sciences defines a functional food as one that encompasses potentially healthy products providing health benefit beyond that of traditional nutrients it contains [9]. This is in agreement with the data of the recent USA study from written questionnaires completed by 2,074 qualified respondents in 1998 indicating that most shoppers believe foods can offer benefits that reach beyond basic nutrition to functional nutrition for disease prevention and health enhancement [10]. Today, functional foods receive extensive attention [11,12] and represent one of the fastest growing divisions of the world food industry [13]. Consumers have also shown interest in purchasing eggs produced by alternative management practices as opposed to conventional production (i.e. cage free, pastured, and free range) [14]. Therefore, the objective of the current study was to assess the effects of marine and flaxseed oil inclusion in diets for pastured laying flocks on hen performance, health, and EPA and DHA content of eggs. 


\section{MATERIALS AND METHODS}

Both experiments housed laying hens in five $3.05 \times 3.05 \mathrm{~m}(10 \times 10 \mathrm{ft})$ mobile poultry houses. Each mobile house was divided into four $1.52 \times 1.52 \mathrm{~m}(5 \times 5 \mathrm{ft})$ pens, providing a total of 20 pens. Each pen was equipped with nipple drinkers [15], a feed hopper [16], six nesting boxes, two doors for outside access as described by Rack and others [17], and netting in order to keep hens confined to each of their respective treatments inside the house. The doors of the houses allowed access to a fenced and netted pasture of $6.40 \times 7.62 \mathrm{~m}(21 \times 25 \mathrm{ft})$. Pastures were equipped with a 26 liter water fount [16]. After two weeks, the hens were moved to an adjacent, identical pasture in order to provide fresh pasture. During daylight hours, hens were given outdoor access and were free to move in and out of the houses. Predation was addressed by surrounding the 5-house production system with electric fence [18], and by locking birds inside houses each night. Hens were exposed to a photoperiod of 14 hours; 4 hours of supplemental lighting each night was provided by a 60 watt incandescent light bulb per house charged by a battery and solar panel. Feed and water were supplied for ad libitum consumption. Hens within each pen were weighed collectively on D1. A colored leg band corresponding to treatment was placed on each hen in order to ensure birds were maintained within their respective treatment groups. Eggs were collected and counted daily. Eggs with cracked shells and/or soft shells were considered losses and not used to calculate egg production data. Eggs were collected the final two days of each study and stored at $4.4^{\circ} \mathrm{C}$ for two weeks prior to analysis to mimic commercial storage times. Four eggs from each diet (within each replicate) were hand separated to remove egg whites. Yolks were lyophilized for 48 hours, ground, and analyzed for fatty acid content [19]. 


\section{Experiment 1}

Experiment 1 was conducted in five mobile poultry houses that provided pasture access and followed management described above. Three hundred, 20-week old SCWL [20] hens were randomly allocated 15 birds per pen and provided one of four randomly assigned diets: 1) Basal;

2) Basal $+0.5 \%$ Sardine Oil; 3) Basal $+1 \%$ Sardine Oil; and 4) Basal $+1 \%$ Flaxseed Oil (Table 1). The basal diet contained a $1 \%$ soybean oil inclusion. For the other three diets, the soybean oil was either partially replaced with $0.5 \%$ Sardine oil, or completely replaced with $1 \%$ sardine oil, or $1 \%$ flaxseed oil. The sardine oil was analyzed for its fatty acid profile [19]. The sardine oil contained 17\% EPA and 11\% DHA and was stabilized with vitamin E [21]. The Basal diet was mixed without oil (68 kg allotments), and when needed, the respective oil was added to the diet prior to feeding. The experimental period spanned 26 days (October through November), and during this time all hens were provided one of the experimental diets as well as pasture. Data was collected to obtain starting and ending bird weight, bird feed intake (FI), bird intake per day, feed:egg, and percent production. Commercially available $\omega-3$ brand eggs [22] and conventionally produced store-brand eggs [23] were used as controls to obtain comparative descriptive data for egg fatty analysis [19].

Sensory Analysis. On the final two days of the experiment, twenty-five eggs from each diet and control eggs were pooled for cooked egg evaluation. Eggs from each diet were handcracked, blended with a wire whisk, and thoroughly cooked as samples were needed. Cooked eggs were portioned into 57, one gram soufflé cups, fitted with lids, and designated a random three digit code [24]. The coded soufflé cups were then stored in a warming oven for no more than 45 minutes to maintain an internal temperature of $140^{\circ} \mathrm{F}$ until testing occurred. Fifty-seven panelists received the scrambled samples and evaluated them on aroma, flavor, texture, visual 
liking, and overall liking using a 9-point hedonic scale, where $1=$ dislike extremely, $2=$ dislike very much, $3=$ dislike moderately, $4=$ dislike slightly, $5=$ neither like nor dislike, $6=$ like slightly, $7=$ like moderately, $8=$ like very much, and $9=$ like extremely [25]. Water and unsalted crackers were provided for panelists to rinse their mouths between each sample. The panelists were also presented with six coded, hardboiled egg halves [26] that were visually evaluated using a 9-point hedonic scale consisting of color and yellowness of the egg yolk.

Colorimetry. Scrambled egg samples from each diet were randomly selected and instrumental color was determined with a CR-300 Minolta Chroma Meter [27] that was calibrated by using a standard white calibration plate. Color measurements were taken on each sample and were expressed in terms of CIE values for lightness $\left(\mathrm{L}^{*}\right)$, redness $\left(\mathrm{a}^{*}\right)$, and yellowness $\left(b^{*}\right)[27]$.

\section{Experiment 2}

Due to the results from the sensory panel and fatty acid analyses from Experiment 1, two diets were chosen to be tested in Experiment 2: Basal (Basal); and Basal + 1\% Sardine Oil (Sardine). This experiment used the same mobile poultry houses as in Experiment 1, as well as a raised wire hen cage system without pasture. The same SCWL hens (now 48 weeks of age) utilized in Experiment 1 were used in this experiment, as well as an additional breed (RS; 48 weeks of age) [28]. Sardine oil was obtained from the same source [21] and contained the same DHA and EPA as Experiment 1. Diets were prepared similarly to that described in Experiment 1. At the farm providing pasture, one hundred SCWL and one hundred RS hens were randomly allocated with 10 birds per pen to one of the two diets. Each one of the five houses had 20 SCWL and 20 RS hens total. Hens kept at the conventionally without pasture access were housed in twenty-four $0.53 \times 0.38 \times 0.51 \mathrm{~m}[1.73 \times 1.25 \times 1.67 \mathrm{ft}]$ raised wire cages equipped 
with nipple drinkers and a feed trough. Twenty-four SCWL and twenty-four RS hens were randomly allocated 2 birds per pen to one of the two experimental diets. The experimental period spanned 40 days (June through July), and during this time measured variables included: beginning and ending bird weight, FI, feed conversion ratio (FCR) based on total egg weight, FCR based on per dozen of eggs laid, and percent lay.

Blood Analyses. To determine bird health, on d 41 and 42, ten hens from each breed, dietary treatment, and housing system ( 80 hens total) were stunned with electricity and exsanguinated via the jugular vein. Blood from each bird was collected in a $25 \mathrm{~mL}$ BD Falcon tube [29] and immediately placed on ice and centrifuged at $1,500 \mathrm{~g}$ for $10 \mathrm{~min}$ at $4^{\circ} \mathrm{C}$ so that nonfasting serum could be collected in a $1 \mathrm{~mL}$ microcentrifuge tube [29] and stored at $-80^{\circ} \mathrm{C}$ until analysis. Serum parameters were determined by Vet- 16 rotor colorimetric assay and measured using a Hemagen Analyst automated spectrophotometer [30]. General clinical health measurements included: alkaline phosphatase (ALP), gamma-glutamyl transpeptidase (GGT), phosphorous (PHOS), albumin (ALB), uric acid (URIC), total protein (TRPO), aspartate aminotransferase (AST), Alanine Aminotransferase (ALT), amylase (AMY), glucose (Gluc), cholesterol (Cholest), urea nitrogen (BUN), calcium, creatine kinase (CK), creatinine, and total bilirubin; and calculates for albumin/globulin ratio (ALBGLOB), globulins (GLOB), and urea nitrogen/creatinine ratio (BUN/CREA). Approximately $90 \mu \mathrm{L}$ of serum was placed in the rotor and the rotor was then placed into the Hemagen Analyst for analysis.

\section{Statistical Analysis}

Experiment 1. Hen performance, egg fatty acid analysis, and sensory analysis variables were analyzed using a randomized complete block design. The experimental unit consisted of one pen of 15 laying hens. Diet means were further explored using Fisher's least significant 
difference test. All data were statistically analyzed using the GLM procedure of Statistical Analysis System [31]. Alpha was designated as 0.05, and letter superscripts were used to denote differences among diet means.

Experiment 2. A housing $\mathrm{X}$ breed $\mathrm{X}$ treatment factorial split plot design was used to explore main effects and interactions of all treatments on performance, fatty acid analysis, and serum chemistry data. Housing was considered the whole plot unit while diet and breed were considered main effects. A randomized complete block design was utilized with one pen of either ten RS or SCWL hens as the experimental unit for hens housed with pasture. For hens housed conventionally without pasture, one pen of either two RS or SCWL hens was the experimental unit. All data were statistically analyzed using the GLM procedure of Statistical Analysis System [31]. Alpha was designated as 0.05, and letter superscripts were used to denote differences among treatment means.

\section{RESULTS AND DISCUSSION}

\section{Experiment 1}

Hen Performance. Beginning bird weight, ending bird weight, bird feed intake (FI), bird intake per day, feed:egg, and percent production were not affected by dietary treatment $(\mathrm{P}>0.05$, Table 2). This is consistent with results observed by Gonzalez-Esquerra and coauthors [32] where fish oil inclusion had no effect on hen weight or egg production during a 19 to $55 \mathrm{wk}$ study period.

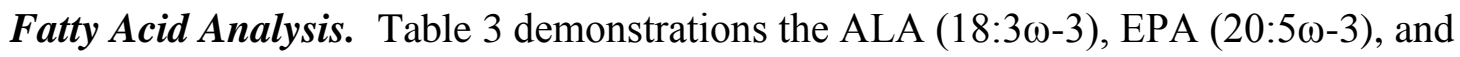

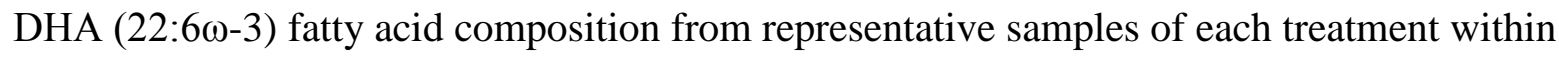
each replicate. Data was analyzed on a percentage of sample basis. There were no significant 
differences among pastured hen egg percent ALA $(\mathrm{P}>0.05)$; however, the pastured hen eggs had a numerically higher percentage of ALA than the descriptive data obtained from the control eggs. Gonzalez-Esquerra and coauthors [32] observed no difference in ALA content when treatments varied by either $2 \%$ regular fish oil or $2 \%$ deodorized fish oil. Hens fed Basal $+1 \%$ Sardine Oil demonstrated the highest percentage of EPA, while hens fed Basal and Basal + 1\% Flaxseed Oil demonstrated the lowest. Hens fed Basal $+0.5 \%$ Sardine Oil demonstrated an intermediate level of EPA percentage $(\mathrm{P}<0.05)$, and the descriptive data obtained from the control eggs contained no detectable EPA. Hens fed Basal $+1 \%$ Sardine Oil provided eggs that had the highest percentage of DHA, while hens fed Basal produced eggs with the lowest DHA content. Hens fed Basal $+0.5 \%$ Sardine Oil and Basal $+1 \%$ Flaxseed Oil produced eggs with an intermediate percentage of DHA $(\mathrm{P}<0.05)$. In addition, all pasture treatments had a numerically higher percentage of DHA than the descriptive data obtained from the control eggs. The increase in percentage of EPA and DHA in eggs as a result of feeding hens fish oil $(\mathrm{P}<0.01)$ was also observed by Gonzalez-Esquerra and coauthors [32]. In our study, hens fed the Basal $+1 \%$ Sardine Oil and Basal $+1 \%$ Flaxseed Oil diets produced eggs with a higher percentage of total $\omega-3$ fatty acids $(\mathrm{P}<0.05)$ compared to hen fed Basal which provided eggs with the lowest percentage. All pasture diets had a numerically higher percentage of total $\omega$-3's compared to the descriptive data obtained from control eggs. There were no significant differences observed for the variable percent $\omega-6$ PUFAs $(\mathrm{P}>0.05)$ among pasture treatments. However, pastured hen eggs had a numerically higher percentage of $\omega-6$ fatty acids compared to the descriptive data obtained from the control eggs. This contrasts results by Van Elswyk and coauthors [33] where a decrease in yolk $\omega-6$ fatty acids was observed due to fish oil inclusion in hen diets. The $\omega-6: \omega-3$ of eggs was highest for hens fed Basal, and lowest for hens fed Basal $+0.5 \%$ Sardine Oil, Basal 
$+1 \%$ Sardine Oil, and Basal $+1 \%$ Flaxseed Oil $(\mathrm{P}<0.05)$. Numerically, the descriptive data obtained from the control eggs had almost double the ratio compared to pastured hen eggs.

An average sized egg weighs approximately $57000 \mathrm{mg}$, and the yolk constitutes about $31 \%$ of the egg weight [34]. Therefore, the weight of an average sized egg yolk is about 18000 $\mathrm{mg}$. The dry matter percentage of an egg yolk is approximately $50 \%$, meaning the dry portion of yolk is $9000 \mathrm{mg}[34,35]$. The eggs in Experiment 1 produced by hens fed Basal $+1 \%$ Maine had an EPA and DHA content of 0.214 and $2.22 \%$ respectively. Knowing that the dry portion of yolk is $9000 \mathrm{mg}$, we can calculate that the EPA and DHA content of these eggs is 19 and 200 $\mathrm{mg} /$ egg respectively. Hens fed Basal $+1 \%$ Sardine produced eggs with a total EPA and DHA content of $219 \mathrm{mg} / \mathrm{egg}$. The American Heart Association advises patients with documented coronary heart disease consume approximately $1000 \mathrm{mg}$ per day of EPA and DHA [36]. Consuming two of the eggs produced by a hen fed the Basal $+1 \%$ Sardine Oil diet in this experiment could provide $40 \%$ of this recommendation.

Sensory Analysis. All sensory analysis data can be found in Table 4 .

Scrambled Samples. There were no significant differences found for aroma, flavor, and visual liking for the scrambled samples $(\mathrm{P}>0.05)$. For texture, eggs collected from hens fed Basal $+1 \%$ Flaxseed Oil and the control eggs received a higher rating, while eggs collected from hens fed Basal $+1 \%$ Sardine Oil $(\mathrm{P}<0.05)$ had the lowest rating. Similar results were found for overall liking $(\mathrm{P}<0.05)$. However, mean ratings did not fall into a category of dislike for any egg.

Hardboiled Samples. The Basal $+0.5 \%$ Sardine Oil eggs had the most appealing color, while the conventionally produced store-brand eggs were the least appealing in color $(\mathrm{P}<0.05)$. Eggs produced by hens fed Basal, Basal $+1 \%$ Sardine Oil, Basal $+1 \%$ Flaxseed Oil, and the 
commercially available $\omega-3$ eggs received an intermediate rating on color. The Basal $+0.5 \%$ Sardine Oil hardboiled eggs obtained the highest rating for yellowness of yolk. The Basal $+1 \%$ Flaxseed Oil and conventionally produced store-brand eggs obtained the faintest yolks (P < 0.05), while hens fed Basal, Basal $+1 \%$ Sardine Oil, and commercially available $\omega-3$ eggs produced eggs with an intermediate yellow yolk. Gonzalez-Esquerra and coauthors [32] also provided hardboiled egg halves to panelists to evaluate different characteristics of the eggs. The scientists found that most of the panelists described the sensory attributes of the eggs produced by hens fed the fish oil as "fishy." The authors of the current study did inquire the panelist about an aftertaste, and received no comments concerning a fishy aftertaste. The current study supplemented Sardine oil at 0.5 and 1\%. However, Gonzalez-Esquerra and coauthors [32] supplemented their diets with 2,4 , and $6 \%$ sardine oil which may have led to the reaction they received.

Colorimetry. All eggs produced by hens with access to pasture were the lightest, while the conventional and commercial $\omega-3$ eggs were darker $(\mathrm{P}<0.05)$. There were no significant differences observed for the variable of redness among the different eggs $(\mathrm{P}>0.05)$. The yellowness was least in the conventionally produced eggs, and greatest in all other pasture produced eggs $(\mathrm{P}<0.05)$. The data for colorimetry can be found in Table 5 .

\section{Experiment 2.}

Hen Performance. Table 6 contains the hen performance data for Experiment 2. The main effect Diet had no effect on hen performance $(\mathrm{P}>0.05)$. Starting bird weight was significantly affected by House and Breed; hens housed conventionally without pasture were larger than hens housed with pasture access and the RS hens were larger than the SCWL $(\mathrm{P}<$ 
0.05). For ending bird weight, there was a House $X$ Breed interaction $(P=0.05)$ describing that the RS hens were larger than the SCWL hens on D40; however, the weight difference was greatest when hens were reared conventionally without pasture. On D40, the main effect Breed influenced FI per bird describing that the RS hens consumed more than the SCWL hens, 5.36 vs. $3.68 \mathrm{~kg}$ per bird, respectively $(\mathrm{P}<0.0001)$. For FCR total egg weight and FCR per dozen, there was a House $\mathrm{X}$ Breed interaction $(\mathrm{P}<0.0001)$ demonstrating that when hens were housed with pasture access, FCR favored SCWL hens; however, when hens were reared conventionally without pasture, FCR favored the RS hens. Percent lay also demonstrated a House X Breed interaction $(\mathrm{P}<0.0001)$ describing that when hens were housed with pasture access, percent lay favored SCWL hens; however, when hens were housed conventionally without pasture, percent lay favored RS hens. These results were likely associated with the RS hens' propensity for foraging and larger body size that would require greater maintenance, and variations in percent lay.

Serum Chemistry. We did not obtain values for several serum measurements using the Hemagen Analyst due to values that were not provided.

Clinical measurements that were obtained can be found in Table 7. ALB and GLOB were not significantly affected by house, breed, or diet $(\mathrm{P}>0.05)$. Still, both ALB and GLOB serum levels on average were in normal range for all hens, $1.3-2.8$ and $1.5-4.1 \mathrm{~g} / \mathrm{dL}$ respectively [37]. For serum ALP activity, the main effect House was significant, demonstrating that hens housed conventionally without pasture had a higher serum ALP activity than hens housed with pasture access, 464.00 vs. $415.53 \mathrm{U} / \mathrm{L}$, respectively $(\mathrm{P}=0.0232)$. The normal ALP serum activity in noncarnivorous birds is less than $10 \mathrm{U} / \mathrm{L}$ [38]. Our ALP value was higher than the normal value. Some medical problems that could have been the cause are 
hyperparathyroidism induced fractures, egg laying, hepatic disease, enteritis, and aflatoxicosis [37]. Özbey and Esen [39] performed a study using rock partridge chicks housed using different stocking densities. There results opposed ours; ALP activity slightly decreased as stocking density decreased. In our study, the main effect House was also significant $(\mathrm{P}<0.0001)$ for serum PHOS and URIC levels, describing that hens housed with pasture access had a higher serum PHOS and URIC levels than hens housed conventionally without pasture. Carpenter [37] states that the normal ranges of PHOS and URIC are $6.2-7.9$ and $2.5-8.1 \mathrm{mg} / \mathrm{dL}$ respectively. URIC serum values for all hens fall into the normal range. PHOS levels, on the other hand, are higher than the normal range (on average about $8.5-9 \mathrm{mg} / \mathrm{dL}$ ). Carpenter [37] explains that this spike could be due to postprandial sampling, severe renal disease, nutritional secondary hyperparathyroidism, or hypoparathyroidism. For serum ALP, GGT, AMY, and Cholest levels, the main effect Breed was significant $(\mathrm{P}<0.05)$ demonstrating that SCWL hens had higher serum ALP, GGT, AMY, and Cholest levels compared to RS hens. Although reference intervals have not been established, the Schubot Exotic Bird Health Center [40] considers the "normal" value of GGT to be $0-10 \mathrm{U} / \mathrm{L}$. We obtained levels that were approximately $25 \mathrm{U} / \mathrm{L}$ greater than the normal range. An increase in GGT activity indicated biliary cholestasis and hyperplasia of bile ducts [41, 42]. Normal serum values for serum AMY in avians ranges between 100 and 600 U/L [43]. All hens demonstrated a normal serum AMY activity. The normal serum Cholest level in chicken is found to be $86-211 \mathrm{mg} / \mathrm{dL}[37,44]$. Both breeds housed at either location and fed either diet had a normal serum Cholest level. The main effect Diet was significant for serum TRPO activity, demonstrating that hens fed Sardine had a higher serum TRPO activity than hens fed Basal; 6.13 vs. $5.73 \mathrm{~g} / \mathrm{dL}$ respectively $(\mathrm{P}=0.0155)$. The normal TRPO activity of a chicken is $3.3-5.5 \mathrm{~g} / \mathrm{dL}$ [37]. We obtained values that were slightly higher than the normal 
value. This could indicate that the hens could have chronic heptopathy, malabsorption, renal disease, or neoplasia [37]. There was a House X Breed interaction $(\mathrm{P}<0.0001)$ for the serum AST level describing that SCWL hens housed conventionally without pasture had the highest serum AST levels, 279.7 U/L. Similar values were also observed by Hrubec and coauthors [45], where they obtained a serum AST value of $219 \mathrm{U} / \mathrm{L}$ using a male single-comb white leghorn model. So and coauthors [46] observed higher serum AST levels in commercial laying hens with fatty liver hemorrhagic syndrome compared to hens without this syndrome. Our serum AST values fell in the healthy range; serum levels greater than $350 \mathrm{U} / \mathrm{L}$ are considered abnormal and are often indicative of liver, muscle, and heart damage [37, 43]. A House X Breed interaction (P $=0.0232$ ) was also found for serum ALT level demonstrating that RS hens had higher serum ALT levels; however, the increase was greater for hens reared conventionally without pasture. The normal range for serum ALT has not been extensively researched, but it has been said to be $1.5-7.5 \mathrm{U} / \mathrm{L}$ [47]. The values we obtained were greater than the normal range. Zantop [48] states that elevated ALT activities can be caused by damage to tissues. For serum Gluc level, a House $\mathrm{X}$ Breed $\mathrm{X}$ Diet interaction $(\mathrm{P}=0.0313)$ was significant demonstrating that hens fed Sardine had higher Gluc levels. For SCWL hens, serum Gluc levels were the highest when hens were housed conventionally without pasture; and for RS hens, levels were the highest when hens were housed with pasture access. The normal serum Gluc range for chicken is $227-350 \mathrm{mg} / \mathrm{dL}$ $[37,49]$. All hens had a serum level within this range indicating that there were no problems with serum Gluc.

Seven out of the twelve serum parameters fell in the normal range. One more than half of the parameters exhibited signs of a healthy avian status; on the other hand, the other five parameters indicated detriment to hen health. The five parameters that were elevated past a 
healthy range were ALP, PHOS, GGT, TRPO, and ALT. However, we did not observed any outward signs of discomfort or sickness nor mortalities throughout the duration of the study. Carpenter [37] states that the increase in serum ALP levels could be due to egg laying, and also explains that the increase in serum PHOS levels could be the cause of postprandial sampling. We obtained serum GGT and ALT levels greater than their normal ranges; however, the normal ranges for serum GGT and ALT have not been extensively researched [40, 47]. Carpenter [37] states that the increase in serum TROP could be caused by a simple means of utilizing a nontemperature compensated refractometer. The authors want to point out that these serum measurements and values are used as a screening method to which a veterinarian may further look into the diagnosis of health issues. Therefore, we can conclude from serum chemistry that we found neither consistent improvement nor detriment to hen health when examining housing environment, breed, and diet.

Egg Fatty Acid Analysis. The fatty acid analysis of eggs produced in Experiment 2 can be found in Table 8, data was analyzed on an mg per egg basis. For EPA content of eggs, there was a House $\mathrm{X}$ Diet interaction $(\mathrm{P}=0.0278)$ describing that hens fed Sardine produced eggs with a higher EPA content; however, the increase was greater for hens reared conventionally without pasture. For DHA, the main effect Diet was significant $(\mathrm{P}<0.0001)$, demonstrating that hens fed Sardine had a higher DHA content compared to hens fed Basal. The highest content of EPA + DHA was achieved in Sardine fed conventionally housed hens (SCWL = $132 \mathrm{mg} / \mathrm{egg}, \mathrm{RS}=$ $141 \mathrm{mg} / \mathrm{egg})$. There was a House X Breed interaction for ALA content of eggs $(\mathrm{P}=0.0002)$ demonstrating that RS hens housed with pasture access produced eggs with the highest ALA content. There was also a House $\mathrm{X}$ Breed interaction for total $\omega-6$ PUFAs content of eggs $(\mathrm{P}=$ 0.0119) demonstrating that SCWL hens produced eggs with a higher total $\omega-6$ content; however, 
the increase was greater for hens reared conventionally without pasture. For total $\omega-3$ content of eggs, there was a House $\mathrm{X}$ Breed interaction $(\mathrm{P}=0.0166)$ describing that the breeds differed most in total $\omega$-3 when hens were provided pasture (RS hens with more and SCWL hens with less content of total $\omega-3$ 's). There was a House X Breed X Diet interaction $(P=0.0229)$ for the ratio of $\omega-6: \omega-3$ content of eggs describing that Basal, lack of pasture, and the SCWL breed contributed to increasing the $\omega-6: \omega-3$ ratio.

The American Heart Association advises patients with coronary heart disease consume approximately $1000 \mathrm{mg}$ per day of EPA and DHA [36]. Consuming two of the eggs produced by a hen fed the Basal $+1 \%$ Sardine Oil diet in this experiment could provide $25 \%$ of this recommendation.

\section{CONCLUSIONS AND APPLICATIONS}

\section{Experiment 1}

1. Hen performance variables were not affected and sensory panel data deemed the eggs produced by hens fed Basal $+1 \%$ Sardine to be acceptable.

2. Hens fed the Basal diet had the lowest EPA and DHA levels, followed by Basal $+0.5 \%$ Sardine Oil and Basal $+1 \%$ Flaxseed Oil. Hens fed the Basal $+1 \%$ Sardine Oil produced eggs with the greatest concentration of EPA and DHA (219 mg/egg total).

3. The Basal $+1 \%$ Sardine eggs were superior to the conventionally produced store-brand eggs for color and yellowness of yolk for hardboiled samples. The authors of the current study did inquire the panelist about an aftertaste, and the panelists replied that there was no fishy aftertaste. 


\section{Experiment 2}

1. Egg DHA content was affected by diet, showing increased DHA when hens were fed Sardine compared to Basal (123 vs. 46 mg/egg, respectively). Egg EPA content was affected by a House X Diet interaction, demonstrating that the hens fed Sardine had elevated EPA; however, the increase was greater when hens were conventionally housed without pasture.

2. Through serum chemistry measurements, we found neither consistent improvement nor detriment to hen health when examining housing environment, breed, and diet.

3. These data show that egg EPA and DHA content can be influenced by both diet and housing system as defined by pasture access.

\section{REFERENCES AND NOTES}

1. Gebauer, S. K., T. L. Psota, W. S. Harris, and P. M. Kris-Etherton. 2006. n-3 Fatty acid dietary recommendations and food sources to achieve essentiality and cardiovascular benefits. Am. J. Clin. Nutr. 83(suppl): 1526S-35S.

2. Gerster, H. 1998. Can adults convert $\alpha$-linolenic acid (18:3n-3) to eicosapentaenoic acid (20:5n-3) and docosahexaenoic acid (22:5n-3)? International Journal of Vitamin and Nutrition Research 68, 159-173.

3. Ratnayake, W. M. N., C. Galli. 2009. Fat and fatty acid terminology, methods of analysis and fat digestion and metabolism: a background review paper. Annual of Nutrition and Metabolism 55:8-43. 
4. Malcolm, C. A., D. L. McCulloch, C. Montgomery, A. Shepherd, L. T. Weaver. 2003. Maternal docosahexaenoic acid supplementation during pregnancy and visual evoked potential development in term infants: a double blind, prospective, randomized trial. Arch Dis Child Fetal Neonat Ed. 88:F383-90.

5. Lauritzen, L., S. H. Jorgensen, T. B. Mikkelsen, M. Skovgaard, E. M. Straarup, S. F. Olsen, C. F. Hoy, K. F. Michaelsen. 2004. Maternal fish oil supplementation in lactation: effect on infant visual acuity and n-3 fatty acid content in infant erythrocytes. Lipids. 39:195-206.

6. Helland, I. B., O. D. Saugstad, L. Smith, K. Saarem, K. Solvoll, T. Ganes, C. A. Drevon. 2001. Similar effects on infants of n-3 and n-6 fatty acids supplementation to pregnant and lactating women. Pediatrics. 108:E82.

7. Calder, P. C. 2006. n-3 polyunsaturated fatty acids, inflammation, and inflammatory diseases. Am. J. Clin. Nutr. 83:1505S-19S.

8. GISSI. 1999. Dietary supplementation with n-3 polyunsaturated fatty acids and vitamin E after myocardial infarction: results of the GISSI-Prevenzione trial. Gruppo Italiano per lo Studio della Sopravvivenza nell'Infarto miocardico. Lancet 354, 447-455.

9. Milner, J. A. 2000. Functional Foods: The US Perspective. Am. J. Clin. Nutr., 71, pp. 1654S-1659S.

10. Gilbert, L. C. 2000. The functional food trend: What's next and what Americans think about eggs. J. Am. Coll. Nutr. 19 (5 Suppl), 507S-512S.

11. Mazza, G. (ed.) 1998. Functional Foods. Biochemical \& Processing Aspects, Technomic Publishing Co. Lancaster/Basel. 
12. Reilly, C. 1998. Se: A New Entrant Into the Functional Food Arena. Trends Food Sci. Technol., 9, pp. 114-118.

13. Harris, C. 2000. Meat Products are Perfect as Functional Foods. Meat Processing $\mathrm{Jan} / \mathrm{Feb}, 19$.

14. Anderson, K. E. 2011. Comparison of fatty acid, cholesterol, and vitamin A and E composition in eggs from hens housed in conventional cage and range production facilities. Poultry Science 90:1600-1608.

15. Ziggity Systems Inc., Middlebury, IN. Customized system designed specifically for facilities at West Virginia University

16. Kuhl Corporation, Flemington, NJ

17. Rack, A. L., K. G. S. Lilly, K. R. Beaman, C. K. Gehring, and J. S. Moritz. 2009. The effect of genotype, choice feeding, and season on organically reared broilers fed diets devoid of synthetic methionine. J. Appl. Poult. Res. 18:54-65.

18. Electronet, a prefabricated fence of electroplastic twines, with plastic posts (every $12 \mathrm{ft}$ ) and vertical plastic struts (every 12 in.). Premier 1 Supplies, Washington, IA

19. New Jersey Feed Laboratory, Ewing, NJ

20. Hy-line International

21. Jedwards International, Inc., Quincy, MA

22. Eggland's Best LLC, Morgantown, WV

23. Kroger Distribution, Morgantown, WV

24. Meilgaard, M., G. V. Civille, and B. T. Carr. 1999. Sensory Evaluation Techniques. 3rd ed. CRC Press Inc., Boca Raton, FL 
25. Peryam, D. R., and F. J. Pilgrim. 1957. Hedonic scale method of measuring food preferences. Food Technol. 11:9-14.

26. USDA Safe Cooking Methods of Hardboiled Eggs; 2013

27. Minolta Co., Ramesy, NJ

28. Murray McMurray Hatchery, Webster City, Iowa.

29. BD Biosciences, Franklin Lakes, NJ

30. Hemagen Diagnostics Inc., Columbia, MD

31. SAS Institute. 2013. The SAS System for Windows 2013. Release 9.3. SAS Inst. Inc., Cary, NC

32. Gonzalez-Esquerra, R. and S. Leeson. 2000. Effect of feeding hens regular or deodorized menhaden oil on production parameters, yolk fatty acid profile, and sensory quality of eggs. Poult. Sci. 79:1597-1602.

33. Van Elswyk, M. E., B. M. Hargis, J. D. Williams, and P. S. Hargis. 1994. Dietary menhaden oil contributes to hepatic lipidosis in laying hens. Poult. Sci. 73:653-662.

34. Johnson, H. S. and S. F. Ridlen. Structure of the Egg. University of Illinois Extension, Incubation and Embryology. http://urbanext.illinois.edu/eggs/res16-egg.html.

35. Ahn, D. Egg Components. Animal Science Department, Iowa State University http://www.public.iastate.edu/ duahn/teaching/Neobiomaterials\%20and\%20Bioregulatio n/Egg\%20Components.pdf.

36. American Heart Association, 2013.

37. Carpenter, J. W. 2013. Exotic animal formulary. $4^{\text {th }}$ ed. Sanders, an imprint by Elsevier Inc., St. Louis, Missouri. 
38. Ebeid, T. A., Y. Z. Eid, and M. M. El-Habbak. 2005. Liver and kidney function parameters in avian species. A review. $3^{\text {rd }}$ International Poultry Conference.

39. Özbey, O. and F. Esen. 2007. The effects of breeding systems and stocking density on some blood parameters of rock partridges (Alectoris graeca). Poul. Sci. 86: 420-422.

40. Schubot Exotic Bird Health Center, College of Veterinary Medicine and Biomedical Sciences. Texas A\&M University. College Station, Texas.

41. Brugere-Picoux, J., H. Brugere, I. Basset, N. Sayad, J. Vaast, and J. M. Michaux. 1983. Acute experimentally induced aflatoxicosis in the weanling pig. American Journal of Veterinary Research 44: 2110-2114.

42. Kramer, J. W. 1989. Clinical Enzimology. In: Kaneko, J. J. (Ed.) Clinical Biochemistry of Domestic Animals, pp. 338-363. (San Diego, CA, Academic Press Inc.).

43. Sakas, P. S. 2002. Understanding avian laboratory tests. Essentials of Avian Medicine: A Practitioner's Guide $2^{\text {nd }}$ Edition. http://nilesanimalhospital.com/files/2012/05/Understanding-Avian-Laboratory-Tests.pdf.

44. Clarenburgh, R. 1992. Physiological Chemistry of Animals. Pp:127.

45. Hrubec, T. C., J. M. Whichard, C. T. Larsen, and F. W. Pierson. 2002. Plasma versus serum: Specific differences in biochemical analyte values. Journal of Avian Medicine and Surgery 16: 101-105.

46. So, H. H., E. O. Jeon, S. H. Byun, and I. P. Mo. 2009. Early diagnosis of fatty liverhemorrhagic syndrome using blood biochemistry in commercial layers. Korean J. Poult. Sci. 36:165-175. 
47. Roland, D. A., D. N. Marple, and R. N. Brewer. 1983. Serum progesterone, enzymes, and electrolytes of hens laying low or high incidence of shell-lee eggs. Poult. Sci. 62: 917922.

48. Zantop, D. W. 1997. Biochemistries. Pages 115-129 in Avian Medicine: Principles and Applications. B. W. Ritchie, G. J. Harrison, and L. R. Harrison, ed. Wingers Publishing Inc., Lake Worth, FL.

49. Campbell T. W. and E. H. Coles. 1986. Avian clinical pathology, In: Veterinary Clinical Pathology. Edited by Coles, E. H. pp: $279-301$.

\section{Acknowledgements}

The authors would like to acknowledge the West Virginia University farm staff, especially Rick Wood for technical support. 
Table 1. Basal Diet Formulation

\begin{tabular}{|c|c|}
\hline Ingredient & Inclusion (\%) \\
\hline Corn & 58.76 \\
\hline Soybean Meal & 19.56 \\
\hline Limestone & 8.97 \\
\hline Corn Gluten Meal & 5.00 \\
\hline Wheat Middlings $^{\prime}$ & 3.88 \\
\hline Defluorinated Phosphorus $^{1}$ & 2.20 \\
\hline Soybean or Sardine Oil $^{1}$ or Flaxseed Oil & 1.00 \\
\hline NB 3000 & 0.25 \\
\hline Salt & 0.13 \\
\hline Methionine & 0.13 \\
\hline Lysine & 0.05 \\
\hline Coban 90 $^{3}$ & 0.05 \\
\hline Phytogenic Feed Additive & 0.02 \\
\hline Calculated Nutrients \\
\hline Metabolizable Energy (kcal/kg) & 2948 \\
\hline Crude Protein (\%) & 18.22 \\
\hline Lysine (\%) & 0.88 \\
\hline Methionine + Cysteine (\%) & 0.76 \\
\hline Calcium (\%) & 4.00 \\
\hline Available Phosphorus (\%) & 0.50 \\
\hline Sodium (\%) & 0.18 \\
\hline
\end{tabular}

${ }^{1}$ Obtained from Jedwards International, Inc., Quincy, MA

${ }^{2}$ Vitamin-mineral premix (NB3000, Nutrablend, Neosho, MO) supplied the following per kilogram of diet: manganese, $0.02 \%$; zinc, $0.02 \%$; iron, $0.01 \%$; copper, $0.0025 \%$; iodine, $0.0003 \%$; selenium, $0.00003 \%$; folic acid, $0.69 \mathrm{mg}$; choline, $386 \mathrm{mg}$; riboflavin, $6.61 \mathrm{mg}$; biotin, $0.03 \mathrm{mg}$; vitamin $\mathrm{B}_{6}, 1.38 \mathrm{mg}$; niacin, $27.56 \mathrm{mg}$; pantothenic acid, $6.61 \mathrm{mg}$; thiamine, $2.20 \mathrm{mg}$; menadione, $0.83 \mathrm{mg}$; vitamin $\mathrm{B}_{12}, 0.01 \mathrm{mg}$; vitamin $\mathrm{E}, 16.53 \mathrm{IU}$; vitamin $\mathrm{D}_{3}$, 2,133 ICU; vitamin A, 7,716 IU.

${ }^{3}$ Active drug ingredient monensin sodium, $60 \mathrm{~g} / \mathrm{lb}$ (90 g/ton inclusion; Elanco Animal Health, Indianapolis, IN) as an aid in the prevention of coccidiosis caused by Eimeria necatrix, Eimeria tenella, Eimeria aceryulina, Eimeria brunette, Eimeria mivati, and Eimeria maxima. 
Table 2. Effects of oil inclusion on laying hen performance data (Experiment 1).

\begin{tabular}{|c|c|c|c|c|c|c|}
\hline Treatment $^{\mathbf{1}}$ & $\begin{array}{c}\text { Beginning Bird } \\
\text { Wt. }^{\mathbf{2}} \mathbf{( k g )}\end{array}$ & $\begin{array}{c}\text { Ending Bird } \\
\mathbf{W t}^{\mathbf{2}} \mathbf{( k g )}\end{array}$ & $\begin{array}{c}\text { Bird Feed } \\
\text { Intake (kg) }\end{array}$ & $\begin{array}{c}\text { Bird Intake } \\
\text { Per Day }\end{array}$ & $\begin{array}{c}\text { Feed:Egg } \\
\text { (kg:dozen) }\end{array}$ & $\begin{array}{c}\text { Percent } \\
\text { Production }(\%)\end{array}$ \\
\hline Basal & 1.29 & 1.23 & 1.72 & 0.07 & 3.77 & 34.81 \\
\hline $\begin{array}{c}\text { Basal + 0.5\% } \\
\text { Sardine Oil }\end{array}$ & 1.28 & 1.23 & 1.54 & 0.06 & 3.24 & 34.63 \\
\hline $\begin{array}{c}\text { Basal + 1\% Sardine } \\
\text { Oil }\end{array}$ & 1.25 & 1.22 & 1.73 & 0.07 & 3.51 & 37.63 \\
\hline $\begin{array}{c}\text { Basal + 1\% } \\
\text { Flaxseed Oil }\end{array}$ & 1.24 & 1.26 & 1.67 & 0.06 & 2.68 & 46.58 \\
\hline ANOVA P-value & 0.3847 & 0.7371 & 0.7894 & 0.7894 & 0.1997 & 0.1066 \\
\hline
\end{tabular}

${ }^{1}$ Treatments: Basal - corn-soybean based diet with a $1 \%$ soybean oil inclusion; Basal + 0.5\% Sardine Oil - corn-soybean based diet with a $0.5 \%$ Sardine oil inclusion; Basal + 1\% Sardine Oil - corn-soybean based diet with a 1\% sardine oil inclusion; Basal + $1 \%$ Flaxseed Oil - corn-soybean based diet with a $1 \%$ flaxseed oil inclusion; All hens were also presented with pasture access

${ }^{2}$ Hens were weighed by pen; however, mean weight per bird is presented 
Table 3. Fatty acid content found performing a fatty acid analysis on eggs collected in this experiment (Experiment 1).

\begin{tabular}{|c|c|c|c|c|c|c|}
\hline Treatment $^{\top}$ & $\operatorname{ALA}^{4}(\%)$ & $\operatorname{EPA}^{5}(\%)$ & $\operatorname{DHA}^{6}(\%)$ & $\omega-3(\%)$ & $\omega-6(\%)$ & $\omega-6: \omega-3$ \\
\hline Basal & 0.15 & $0.048^{\mathrm{c}}$ & $1.07^{\mathrm{c}}$ & $2.04^{c}$ & 20.29 & $10.46^{\mathrm{a}}$ \\
\hline Basal $+0.5 \%$ Sardine Oil & 0.15 & $0.124^{\mathrm{b}}$ & $1.92^{\mathrm{b}}$ & $2.95^{\mathrm{b}}$ & 19.41 & $6.58^{b}$ \\
\hline Basal $+1 \%$ Sardine Oil & 0.128 & $0.214^{\mathrm{a}}$ & $2.22^{\mathrm{a}}$ & $3.50^{\mathrm{ab}}$ & 20.29 & $5.84^{b}$ \\
\hline Basal + 1\% Flaxseed Oil & 0.13 & $0.082^{\mathrm{c}}$ & $1.67^{b}$ & $3.87^{\mathrm{a}}$ & 20.47 & $5.35^{b}$ \\
\hline ANOVA P-value & 0.0791 & $<0.0001$ & $<0.0001$ & 0.0003 & 0.1785 & 0.0003 \\
\hline Fisher's LSD & --- & 0.0414 & 0.2626 & 0.6372 & --- & 1.9239 \\
\hline \multicolumn{7}{|c|}{ Descriptive Data } \\
\hline Commercially available $\omega-3^{2}$ & 0.06 & 0 & 0.72 & 1.3 & 11.46 & 8.8 \\
\hline Conventionally produced ${ }^{3}$ & 0.05 & 0 & 0.23 & 0.67 & 11.78 & 17.5 \\
\hline
\end{tabular}

${ }^{\mathrm{a}-\mathrm{c}}$ Values within comparisons with different superscripts differ $(\mathrm{P} \leq 0.05)$

${ }^{1}$ Treatments: Basal - corn-soybean based diet with a $1 \%$ soybean oil inclusion; Basal $+0.5 \%$ Sardine Oil - corn-soybean based diet with a $0.5 \%$ sardine oil inclusion; Basal $+1 \%$ Sardine Oil - corn-soybean based diet with a $1 \%$ sardine oil inclusion; Basal + 1\% Flaxseed Oil - corn-soybean based diet with a $1 \%$ flaxseed oil inclusion; All hens were also presented with pasture access

${ }^{2}$ Commercially available $\omega-3$ - Eggland's Best eggs

${ }^{3}$ Conventionally produced - Kroger brand eggs

${ }^{4}$ ALA (alpha-linolenic acid (ALA, 18:3 $\omega$-3))

${ }^{5}$ EPA (eicosapentaenoic acid (EPA, 20:5 $\left.\omega-3\right)$ )

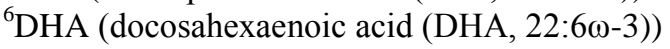


Table 4. Sensory Analysis (Experiment 1).

\begin{tabular}{|c|c|c|c|c|c|c|c|}
\hline \multirow{2}{*}{ Treatment $^{1}$} & \multicolumn{5}{|c|}{ Scrambled Samples } & \multicolumn{2}{|c|}{ Hardboiled Samples } \\
\hline & Aroma & Flavor & Texture & Visual Liking & Overall Liking & Color & Yellowness of Yolk \\
\hline Basal & 5.31 & 5.28 & $5.51^{\mathrm{ab}}$ & 5.65 & $5.33^{\mathrm{ab}}$ & $4.91^{b}$ & $5.76^{\mathrm{b}}$ \\
\hline $\begin{array}{c}\text { Basal + 0.5\% } \\
\text { Sardine Oil }\end{array}$ & 4.91 & 5.53 & $5.64^{\mathrm{ab}}$ & 5.69 & $5.65^{\mathrm{ab}}$ & $7.04^{\mathrm{a}}$ & $6.87^{\mathrm{a}}$ \\
\hline $\begin{array}{l}\text { Basal + 1\% } \\
\text { Sardine Oil }\end{array}$ & 4.77 & 4.84 & $5.00^{\mathrm{b}}$ & 5.02 & $4.75^{b}$ & $4.65^{\mathrm{b}}$ & $5.51^{\mathrm{b}}$ \\
\hline $\begin{array}{c}\text { Basal + 1\% } \\
\text { Flaxseed Oil }\end{array}$ & 5.45 & 5.70 & $6.14^{\mathrm{a}}$ & 5.82 & $6.02^{\mathrm{a}}$ & $4.04^{\mathrm{b}}$ & $4.59^{\mathrm{c}}$ \\
\hline $\begin{array}{l}\text { Commercially } \\
\text { available } \omega-3^{2}\end{array}$ & 5.10 & 5.63 & $6.05^{\mathrm{a}}$ & 5.77 & $5.91^{\mathrm{a}}$ & $4.65^{\mathrm{b}}$ & $5.51^{\mathrm{b}}$ \\
\hline $\begin{array}{c}\text { Conventionally } \\
\text { produced }^{3}\end{array}$ & 5.35 & 5.41 & $6.07^{\mathrm{a}}$ & 5.96 & $5.76^{\mathrm{a}}$ & $3.15^{\mathrm{c}}$ & $3.71^{\mathrm{c}}$ \\
\hline ANOVA P-value & 0.2838 & 0.1499 & 0.0018 & 0.091 & 0.001 & $<0.0001$ & $<0.0001$ \\
\hline
\end{tabular}

${ }^{\mathrm{a}-\mathrm{c}}$ Values within comparisons with different superscripts differ $(\mathrm{P} \leq 0.05)$

${ }^{1}$ Treatments: Basal - corn-soybean based diet with a $1 \%$ soybean oil inclusion; Basal $+0.5 \%$ Sardine Oil - corn-soybean based diet with a $0.5 \%$ Sardine oil inclusion; Basal + 1\% Sardine Oil - corn-soybean based diet with a 1\% Sardine oil inclusion; Basal + 1\% Flaxseed Oil - corn-soybean based diet with a $1 \%$ flaxseed oil inclusion; All hens were also presented with pasture access

${ }^{2}$ Commercially available $\omega-3$ - Eggland's Best eggs

${ }^{3}$ Conventionally produced - Kroger brand eggs

${ }^{4} 9$-point hedonic scale, where 1 = dislike extremely, $5=$ neither like nor dislike, and $9=$ like extremely [Peryam, D. R., and F. J. Pilgrim. 1957. Hedonic scale method of measuring food preferences. Food Technol. 11:9-14.]. 
Table 5. Colorimetry (Experiment 1).

\begin{tabular}{|c|c|c|c|}
\hline Treatment $^{1}$ & $\mathbf{L}^{*^{4}}$ & $\mathbf{a}^{*^{4}}$ & $\mathbf{b}^{*^{4}}$ \\
\hline Basal & $56.33^{\mathrm{a}}$ & -3.37 & $43.35^{\mathrm{a}}$ \\
\hline Basal + 0.5\% Sardine Oil & $48.24^{\mathrm{ab}}$ & -2.83 & $35.32^{\mathrm{a}}$ \\
\hline Basal + 1\% Sardine Oil & $50.53^{\mathrm{ab}}$ & -3.57 & $34.88^{\mathrm{a}}$ \\
\hline Basal + 1\% Flaxseed Oil & $53.12^{\mathrm{ab}}$ & -3.18 & $39.21^{\mathrm{a}}$ \\
\hline Commercially available $\omega-3$ & $47.32^{\mathrm{bc}}$ & -2.40 & $32.55^{\mathrm{ab}}$ \\
\hline Conventionally produced & $39.42^{\mathrm{c}}$ & -3.62 & $22.49^{\mathrm{b}}$ \\
\hline ANOVA P-value & 0.0003 & 0.2 & 0.001 \\
\hline Fisher's LSD & 5.3 & --- & 7.32 \\
\hline
\end{tabular}

${ }^{\mathrm{a}-\mathrm{c}}$ Values within comparisons with different superscripts differ $(\mathrm{P} \leq 0.05)$

${ }^{1}$ Treatments: Basal - corn-soybean based diet with a $1 \%$ soybean oil inclusion; Basal $+0.5 \%$ Sardine Oil - corn-soybean based diet with a $0.5 \%$ Sardine oil inclusion; Basal + 1\% Sardine Oil - corn-soybean based diet with a 1\% Sardine oil inclusion; Basal + 1\% Flaxseed Oil - corn-soybean based diet with a 1\% flaxseed oil inclusion; All hens were also presented with pasture access

${ }^{2}$ Commercially available $\omega-3$ - Eggland's Best eggs

${ }^{3}$ Conventionally produced - Kroger brand eggs

${ }^{4} \mathrm{CIE}$ values for lightness $\left(\mathrm{L}^{*}\right)$, redness $\left(\mathrm{a}^{*}\right)$, and yellowness $\left(\mathrm{b}^{*}\right)$. Color measurements were taken on each sample using a CR-300 Minolta Chroma Meter

[Minolta Co., Ramesy, NJ] 
Table 6. Effects of housing environment, breed, and diet on laying hen performance (Experiment 2).

\begin{tabular}{|c|c|c|c|c|c|c|c|c|}
\hline $\begin{array}{c}\text { Housing } \\
\text { Environment }\end{array}$ & Breed & Diet & $\begin{array}{c}\text { Average } \\
\text { Starting Bird } \\
\text { Weight }^{1}(\mathrm{~kg}) \\
\end{array}$ & $\begin{array}{l}\text { Ending Bird } \\
\text { Weight }^{1}(\mathrm{~kg})\end{array}$ & $\begin{array}{c}\text { Feed } \\
\text { Intake/Bird } \\
(\mathbf{k g}) \\
\end{array}$ & $\begin{array}{c}\text { FCR Total Egg } \\
\text { Weight (g:g) }\end{array}$ & $\begin{array}{c}\text { FCR per } \\
\text { Dozen } \\
\text { (kg:dozen) }\end{array}$ & $\begin{array}{c}\text { Percent } \\
\text { Lay }\end{array}$ \\
\hline \multicolumn{9}{|c|}{ Marginal Means } \\
\hline Pasture $^{2}$ & --- & --- & $1.58^{\mathrm{b}}$ & 1.62 & 4.60 & 3.03 & $2.37^{\mathrm{a}}$ & $64.00^{b}$ \\
\hline Conventional $^{3}$ & --- & --- & $1.68^{\mathrm{a}}$ & 1.67 & 4.44 & 2.91 & $1.91^{\mathrm{b}}$ & $74.00^{\mathrm{a}}$ \\
\hline \\
\hline--- & $\mathrm{SCWL}^{4}$ & --- & $1.37^{b}$ & $1.32^{b}$ & $3.68^{b}$ & $2.66^{b}$ & $1.82^{b}$ & $64.00^{b}$ \\
\hline--- & $\mathrm{RS}^{5}$ & --- & $1.89^{\mathrm{a}}$ & $1.97^{\mathrm{a}}$ & $5.36^{\mathrm{a}}$ & $3.29^{\mathrm{a}}$ & $2.46^{\mathrm{a}}$ & $74.00^{\mathrm{a}}$ \\
\hline--- & --- & Basal $^{6}$ & 1.62 & 1.64 & 4.62 & 2.97 & 2.16 & 69.00 \\
\hline--- & --- & Sardine $^{7}$ & 1.64 & 1.65 & 4.41 & 2.97 & 2.11 & 69.00 \\
\hline \multicolumn{9}{|c|}{ Main Effects and Interaction Probabilities } \\
\hline \multicolumn{3}{|c|}{ Effect } & \multicolumn{6}{|c|}{$\mathbf{P}>\mathbf{F}$} \\
\hline \multicolumn{3}{|c|}{ House } & 0.0009 & 0.0648 & 0.2097 & 0.3682 & 0.0002 & 0.0196 \\
\hline \multicolumn{3}{|c|}{ Breed } & $<0.0001$ & $<0.0001$ & $<0.0001$ & 0.0007 & $<0.0001$ & 0.0245 \\
\hline \multicolumn{3}{|c|}{ House $\mathrm{x}$ Breed } & 0.2970 & 0.0500 & 0.5259 & $<0.0001$ & $<0.0001$ & $<0.0001$ \\
\hline \multicolumn{3}{|c|}{ House $\mathrm{x}$ Diet } & 0.4109 & 0.8745 & 0.7965 & 0.8006 & 0.9307 & 0.7667 \\
\hline \multicolumn{3}{|c|}{ Breed x Diet } & 0.1197 & 0.2146 & 0.6506 & 0.4475 & 0.6934 & 0.7421 \\
\hline \multicolumn{3}{|c|}{ House x Breed x Diet } & 0.4209 & 0.2304 & 0.4679 & 0.3136 & 0.4951 & 0.2628 \\
\hline
\end{tabular}

${ }^{\mathrm{a}-\mathrm{c}}$ Values within comparisons with different superscripts $\operatorname{differ}(\mathrm{P} \leq 0.05)$

${ }^{1}$ Hens were weighed by pen, however, mean weight per bird is presented

${ }^{2}$ Pasture - hens housed with provided pasture access

${ }^{3}$ Conventional - hens housed conventionally without pasture

${ }^{4}$ SCWL (Hy-line W36 Single Comb White Leghorn hen [Hy-line])

${ }^{5} \mathrm{RS}$ (Red Star hen)

${ }^{6} \mathrm{Basal}$ - corn-soybean based diet with a $1 \%$ soybean oil inclusion

${ }^{7}$ Sardine - corn-soybean based diet with a $1 \%$ sardine oil inclusion 
Table 7. Effects of housing environment, breed, and diet on serum chemistry (Experiment 2).

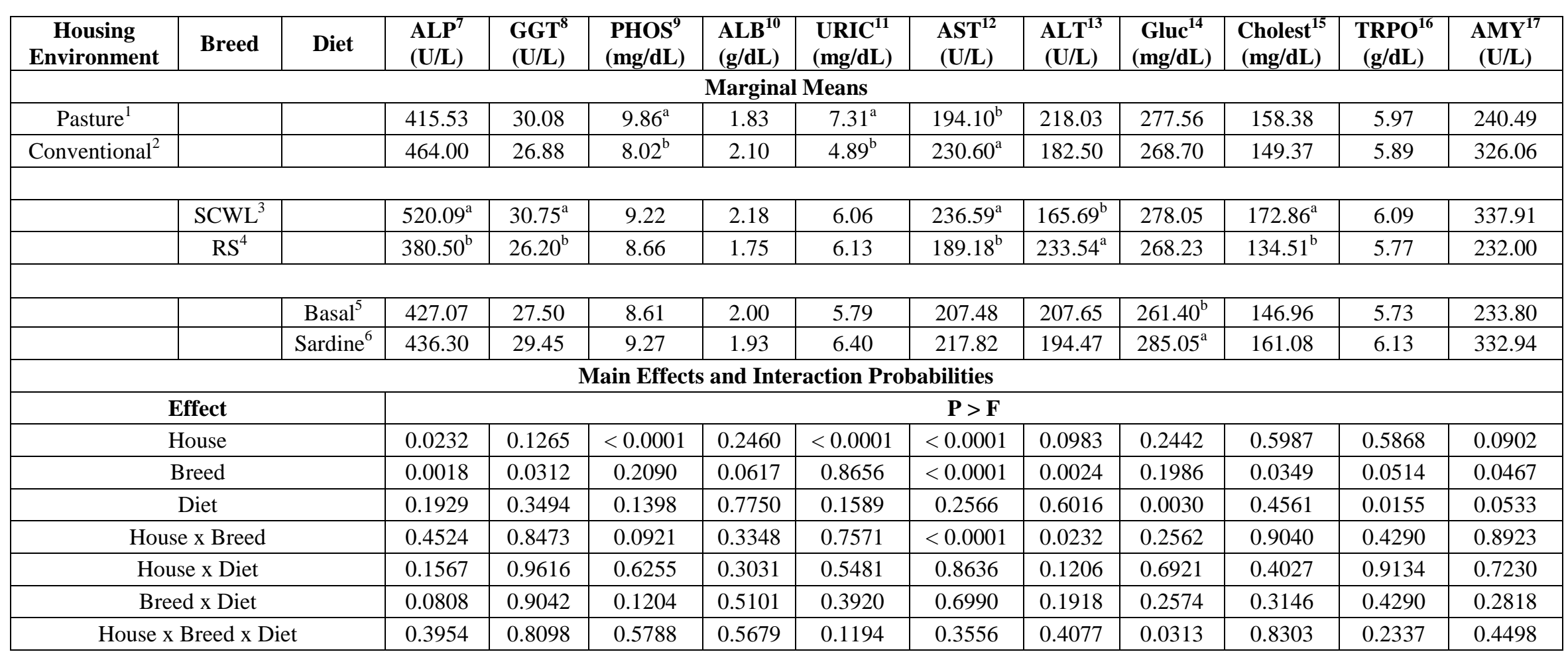

${ }^{\mathrm{a}-\mathrm{d},}$ Values within comparisons with different superscripts $\operatorname{differ}(\mathrm{P} \leq 0.05)$

${ }^{1}$ Pasture - hens housed with provided pasture access

${ }^{9} \mathrm{PHOS}$ (phosphorous)

${ }^{2}$ Conventional - hens housed conventionally without pasture access

${ }^{3}$ SCWL (Hy-line W36 Single Comb White Leghorn hen [Hy-line])

${ }^{4} \mathrm{RS}$ (Red Star hen)

${ }^{5} \mathrm{Basal}$ - corn-soybean based diet with a $1 \%$ soybean oil inclusion

${ }^{6}$ Sardine - corn-soybean based diet with a $1 \%$ sardine oil inclusion

${ }^{7}$ ALP (alkaline phosphatase

${ }^{8}$ GGT (gamma-glutamyl transpeptidase))

${ }^{10}$ ALB (albumin)

${ }^{11}$ URIC (uric acid)

${ }^{12}$ AST (aspartate aminotransferase)

${ }^{13}$ ALT (alanine aminotransferase)

${ }^{14}$ Gluc (glucose)

${ }^{15}$ Cholest (cholesterol)

${ }^{16}$ TRPO (total protein)

${ }^{17}$ AMY (amylase) 
Table 8. Effects of housing environment, breed, and diet on fatty acid content of eggs collected in this experiment (Experiment 2

\begin{tabular}{|c|c|c|c|c|c|c|c|c|c|}
\hline $\begin{array}{c}\text { Housing } \\
\text { Environment }\end{array}$ & Breed & Diet & $\begin{array}{c}\text { Yolk Size } \\
\text { (kg) }\end{array}$ & $\begin{array}{c}\mathbf{E P A}^{7} \\
(\mathrm{mg} / \mathrm{egg})\end{array}$ & $\begin{array}{c}\text { DHA }^{8} \\
(\mathrm{mg} / \mathrm{egg})\end{array}$ & $\begin{array}{c}\mathrm{ALA}^{9} \\
(\mathrm{mg} / \mathrm{egg})\end{array}$ & $\begin{array}{c}\text { Total } \omega-3 \\
(\mathrm{mg} / \mathrm{egg})\end{array}$ & $\begin{array}{c}\text { Total } \omega-6 \\
(\mathrm{mg} / \mathrm{egg})\end{array}$ & $\omega-6: \omega-3$ \\
\hline \multicolumn{10}{|c|}{ Marginal Means } \\
\hline Pasture $^{1}$ & -- & --- & 0.01 & $2.70^{\mathrm{b}}$ & 84.11 & $30.33^{\mathrm{a}}$ & 121.21 & 889.30 & $8.66^{b}$ \\
\hline Conventional $^{2}$ & --- & --- & 0.01 & $5.51^{\mathrm{a}}$ & 87.07 & $24.51^{b}$ & 123.10 & 867.44 & $8.95^{\mathrm{a}}$ \\
\hline--- & $\mathrm{SCWL}^{3}$ & --- & 0.01 & 3.66 & 83.01 & $29.79^{\mathrm{a}}$ & 120.75 & $938.65^{\mathrm{a}}$ & $9.14^{\mathrm{a}}$ \\
\hline--- & $\mathrm{RS}^{4}$ & --- & 0.01 & 4.46 & 87.96 & $25.31^{b}$ & 123.45 & $821.65^{b}$ & $8.48^{b}$ \\
\hline--- & --- & Basal $^{5}$ & 0.01 & $0^{\mathrm{b}}$ & $46.23^{b}$ & $29.81^{\mathrm{a}}$ & $76.04^{b}$ & $986.41^{\mathrm{a}}$ & $13.08^{\mathrm{a}}$ \\
\hline--- & --- & Sardine $^{6}$ & 0.01 & $7.93^{\mathrm{a}}$ & $122.90^{\mathrm{a}}$ & $25.30^{b}$ & $165.91^{\mathrm{a}}$ & $776.28^{b}$ & $4.74^{b}$ \\
\hline \multicolumn{10}{|c|}{ Main Effects and Interaction Probabilities } \\
\hline \multicolumn{3}{|c|}{ Effect } & \multicolumn{7}{|c|}{$\mathbf{P}>\mathbf{F}$} \\
\hline \multicolumn{3}{|c|}{ House } & 0.3862 & 0.0278 & 0.7498 & 0.0001 & 0.9710 & 0.7480 & 0.0422 \\
\hline \multicolumn{3}{|c|}{ Breed } & 0.2698 & 0.3780 & 0.0613 & 0.0008 & 0.3351 & 0.0002 & 0.0011 \\
\hline \multicolumn{3}{|c|}{ Diet } & 0.3333 & $<0.0001$ & $<0.0001$ & 0.0008 & $<0.0001$ & $<0.0001$ & $<0.0001$ \\
\hline \multicolumn{3}{|c|}{ House x Breed } & 0.7742 & 0.5187 & 0.0985 & 0.0002 & 0.0166 & 0.0119 & 0.0330 \\
\hline \multicolumn{3}{|c|}{ House x Diet } & 0.8712 & 0.0278 & 0.3890 & 0.9975 & 0.1423 & 0.2995 & 0.0004 \\
\hline \multicolumn{3}{|c|}{ Breed x Diet } & 0.6847 & 0.3780 & 0.0784 & 0.8959 & 0.0673 & 0.6935 & 0.1518 \\
\hline \multicolumn{3}{|c|}{ House $x$ Breed $x$ Diet } & 0.2825 & 0.5187 & 0.3735 & 0.9581 & 0.6670 & 0.6204 & 0.0229 \\
\hline
\end{tabular}

${ }^{\text {a-e }}$ Values within comparisons with different superscripts differ $(\mathrm{P} \leq 0.05)$

${ }^{1}$ Pasture - hens housed with provided pasture access

${ }^{2}$ Conventional - hens housed conventionally without pasture access

${ }^{3}$ SCWL (Hy-line W36 Single Comb White Leghorn hen [Hy-line])

${ }^{4} \mathrm{RS}$ (Red Star hen)

${ }^{5}$ Basal - corn-soybean based diet with a $1 \%$ soybean oil inclusion

${ }^{6}$ Sardine - corn-soybean based diet with a $1 \%$ sardine oil inclusion

${ }^{7}$ EPA (eicosapentaenoic acid (20:5 $\left.\omega-3\right)$ )

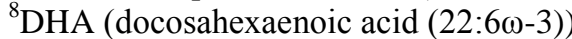

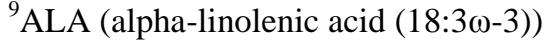


CHAPTER3: The Effects of Pelleting and Glucanase Supplementation in Hulled Barley Based Diets on Feed Manufacture, Broiler Performance, and Digesta Viscosity

A.E. Lamp ${ }^{*}$ and J.S. Moritz ${ }^{*}, 1$

* Division of Animal and Nutritional Sciences, West Virginia University, Morgantown 26506

${ }^{1}$ Corresponding author: Joe.Moritz@mail.wvu.edu

Keywords: glucanase, feed manufacture, digesta viscosity, broiler performance

Primary Audience: Nutritionists, Researchers 


\section{SUMMARY}

Feeding broilers barley based diets, high in beta-glucan, requires special consideration primarily due to effects on increased digesta viscosity (DV) and decreased nutrient digestion. Pelleting and glucanse (gluc) supplementation are common practices utilized prior to feeding broilers barley based diets; however, the interaction of these practices is complex. Thermal processing and gluc supplementation have been shown to have opposing effects on DV; and if gluc is added at the mixer, then gluc thermal stability becomes a concern. The study utilized a randomized complete block design with eight replications of 10 straight-run Cobb x Cobb 500 broilers. Dietary treatments varied in gluc dose (125 - 2000U/kg of feed), gluc enzyme type (GA and GB), and degree of processing (unprocessed mash and ground pellet). Broilers fed ground pellets had a greater pen feed intake (FI) compared to birds fed unprocessed mash diets. Inclusion of GA decreased DV and increased weight gain for ground pelleted diets, but not unprocessed mash diets. For ground pellets, GA dosed at $1000 \mathrm{U} / \mathrm{kg}$ of feed was superior to the negative control (150 kcal/kg energy decrease) and indistinguishable from the positive control for ending bird weight and weight gain. These benefits were not observed for GB, perhaps in part due to a 50\% decrease in activity post pelleting. Evaluations of gluc should go beyond in vitro activity and include live bird performance using feed that has undergone pelleting.

\section{DESCRIPTION OF PROBLEM}

Barley use in poultry diets has been traditionally limited in the United States due to its low energy value and subsequent sticky droppings, impairment of broiler performance, and decrease of digestion and absorption of nutrients [1,2]. However, today barley is being used more 
frequently as a diet component because of the better knowledge of its chemical composition and the remarkable progress in biotechnological production of commercial enzymes [3, 4].

The addition of a gluc enzyme to a barley based broiler diet can provide several benefits. The enzyme can improve the efficiency of feed utilization, contribute to a better use of low cost feed ingredients [5, 6], reduce sticky droppings [1], and improve digestion and absorption of starch, protein, and fat $[7,8]$. These factors all lead to increased broiler productivity.

Thermal stability throughout the pelleting process is a major concern for any mixer-added enzyme $[9,10]$. It has been proposed that most inactivation of mixer-added enzymes take place during conditioning, when the feed is heated with saturated steam, rather than during extrusion of feed through the pellet die [11]. However, some studies have proposed mixer-added enzyme inactivation to be associated with frictional heat and pressure in the pellet die [12].

Past research has varied in methods and results on testing the thermal stability of $\beta$-gluc. Inborr and Bedford [13] tested thermal stability of a commercial $\beta$-gluc feed enzyme product (Avizyme $\left.\mathrm{SX}^{\circledR}\right)$ at three levels of inclusion $(0,1$, and $10 \mathrm{~g} / \mathrm{kg})$ to a barley and wheat based diet. Based on bird performance, the scientists concluded that conditioning a feed and enzyme mixture at $85^{\circ} \mathrm{C}$ did not reduce enzyme activity compared to $75^{\circ} \mathrm{C}$; however, $95^{\circ} \mathrm{C}$ conditioning caused significant inactivation. Esteve-Garcia and coauthors [9] tested the effects of pelleting wheat and barley diets supplemented with $\beta$-gluc (added as $2 \%$ of the total mix) at temperatures around $80^{\circ} \mathrm{C}$ and found that the enzymes maintained over $80 \%$ activity. Conversely, Almirall and Esteve-Garcia [14] incubated $4000 \mathrm{U} / \mathrm{mL}$ of $\beta$-gluc obtained from Trichoderma longibrachiatum in solution at $70^{\circ} \mathrm{C}, 80^{\circ} \mathrm{C}$, and $100^{\circ} \mathrm{C}$ and found that activity was reduced to 65,20 , and $0 \%$ respectively of original dose activity [9]. 
The objective of this study was to evaluate dosages of gluc preparations added at the mixer to barley based diets ( $45 \%$ of diet formulation) in unprocessed mash and ground pelleted diets on broiler performance and DV. Feeding ground pellets allows for thermal processing effects to be demonstrated without being confounded by feed form effects.

\section{MATERIALS AND METHODS}

\section{Glucanase Enzyme}

Two different experimental, mixer-added gluc enzymes were tested in this experiment: Glucanase A (GA) and Glucanase B (GB). GA was tested at four doses: 125, 500, 1000, and 2000 Units/kg of feed; and GB was tested at 1000 Units/kg of feed. GA was in an earlier stage of development; therefore, more doses were required to examine enzyme efficacy. GB was a more established candidate; therefore, fewer doses were associated with the enzyme. The enzyme was mixed with a $3 \mathrm{~kg}$ sample of complete $\mathrm{NC}$ feed in a small paddle mixer then remixed with 500 or $200 \mathrm{~kg}$ of the remaining NC complete feed batch depending on the treatment. The remixing took place in a single-screw vertical mixer [15].

\section{Diet Formulations}

Diets consisted of positive control (PC) and negative control (NC) formulation that were based on industry recommendations and digestible amino acid matrices and differed by 150 $\mathrm{kcal} / \mathrm{kg}$ (Table 1). The NC diet had the gluc enzymes added on top of the formulation at the mixer. A total of 12 diets were fed (Table 2).

\section{Feed Manufacture}

All feed was manufactured at the West Virginia University pilot feed mill. A total of 500 $\mathrm{kg}$ of feed was batched according to the PC diet formulation. This was then split into two $250 \mathrm{~kg}$ 
batches. The first $250 \mathrm{~kg}$ batch was mixed and fed as PC unprocessed mash. The second $250 \mathrm{~kg}$ batch was conditioned using a short-term conditioner $(0.31 \times 1.30 \mathrm{~m}, 10$-s retention time $)$ [16] with a constant temperature of $80^{\circ} \mathrm{C}$ and an incoming gauge steam pressure prior to the conditioner of $262 \mathrm{kPa}$. Pellets were then extruded using a 40-horsepower California pellet mill [17] with a 4.76 (effective thickness) x $38.1 \mathrm{~mm}$ (length) pellet die without relief. These pellets were then ground using a roller mill and fed as PC ground pellets. Feeding ground pellets allows for thermal processing effects to be demonstrated without being confounded by feed form effects. A total of 2,400 $\mathrm{kg}$ of feed was mixed according to the NC diet formulation. This was then split into six allotments: four allotments contained $500 \mathrm{~kg}$ each and two allotments contained $200 \mathrm{~kg}$ each. One of the four allotments containing $500 \mathrm{~kg}$ was kept as is and the other three were mixed with either GA 125 U/kg of feed, GA 1000 U/kg feed, or GB 1000 U/kg feed. These four allotments were then split into two $250 \mathrm{~kg}$ batches, creating a total of eight $250 \mathrm{~kg}$ batches. The first batch of $250 \mathrm{~kg}$ was mixed and fed as unprocessed mash, and the second 250 $\mathrm{kg}$ batch was pelleted following the process described for the PC diet and fed as ground pellets. The two allotments containing $200 \mathrm{~kg}$ were either mixed with GA 500 or $2000 \mathrm{U} / \mathrm{kg}$ feed, remixed, and fed as unprocessed mash.

\section{Feed Sampling}

Average hot pellet temperature (HPT), pellet durability index (PDI), and percent pellets were recorded as descriptive data during and post manufacture (Table 2). Measures of HPT were obtained by placing an insulated container under the pellet mill, catching hot pellets, immediately closing the lid, and use of a thermocouple thermometer [18] and an 80PK-24 temperature probe. This procedure was performed four times during the run then averaged. Measurements of PDI were obtained using the New Holmen Pellet Tester [19] where one 
hundred grams of pelleted samples are subjected to air flow within a perforated chamber for 30 seconds. Measurements of percent pellets were obtained using approximately $2.3 \mathrm{~kg}$ of pelleted samples sifted through a Tyler No. 6 screen. The remaining pellets on the screen were recorded as the percentage of pellets for each treatment.

\section{Enzyme Activity}

The target enzyme activities for GA were 125, 500, 1000, and $2000 \mathrm{U} / \mathrm{kg}$ of feed. The target enzyme activity for GB was $1000 \mathrm{U} / \mathrm{kg}$ of feed. A day after manufacture, all 12 dietary treatments were sent to a commercial laboratory for assessment of gluc activity [20]. A dinitrosalicyclic acid (DNS) assay was performed on the processed and unprocessed feed to determine enzyme activity and retention. This assay uses dinitrosalicylic acid as a color developing agent and measures the amount of $\beta$-glucan cleaved by the $\beta$-gluc [21]. First, 0.250 $\mathrm{ml}$ of substrate solution (Azo-b-glucan, Megazyme, Ireland) was added to $0.250 \mathrm{ml}$ of extract. After 30 min of incubation at $50^{\circ} \mathrm{C}$ the reaction was stopped by adding $1 \mathrm{ml}$ of precipitant (Naacetate $3 \mathrm{H}_{2} \mathrm{O} 4 \%$; $\mathrm{Zn}$-acetate $0.4 \% ; 800 \mathrm{ml}$ methoxyethanol; water to make 1 liter (pH 5)) and vigorous stirring. After $30 \mathrm{~min}$ the tubes were centrifuged for $10 \mathrm{~min}$ at $1500 \mathrm{x} \mathrm{g}$ and the optical density of the supernatant was read at $585 \mathrm{~nm}$. A standard curve was plotted as the optical density released versus the amount of enzyme added (in grams of enzyme per tonne of feed, ppm). The residual enzyme activity of the studied sample was read on the standard curve [21]. Typically this is used on pure enzyme (not in animal feed), but the assay was adapted to use it for feed reliably. The results of the DNS assay can be found in Figure 1.

\section{Live Bird Performance}

A total of 960 day-old Cobb x Cobb 500 [22] straight run chicks were obtained from a commercial hatchery [23]. On D1, the chicks were weighed ten birds at a time and were 
allocated to 96 raised wire cages based on weight to create uniform initial pen weights. One of the twelve diets was randomly assigned to each pen within a block. A block consisted of 12 adjacent cages, and there were eight blocks or replications. Chicks were housed in raised wire cages in a cross-ventilated, negative-pressure room. Two identical rooms were utilized; each containing 48 cages, creating a total of 96 cages. Room temperature for the day-old chicks was set at $32^{\circ} \mathrm{C}\left(90^{\circ} \mathrm{F}\right)$; and gradually decreased to $29^{\circ} \mathrm{C}\left(85^{\circ} \mathrm{F}\right)$ for the second week and $26^{\circ} \mathrm{C}\left(80^{\circ} \mathrm{F}\right)$ for the third week of the study to create optimal rearing conditions. Feed was placed in external feed troughs and water was supplied through a nipple drinker system; both feed and water were provided for ad libitum consumption. Lighting was manipulated through grow-out to ensure that birds had a full gastro intestinal tract when sampled on D21. From D1 to D6 birds were exposed to 24 hours of light, and after D6, the hours of light were decreased gradually until six hours of dark was reached on D20 and 21. On D21, birds were exposed to six hours dark and then allowed to consume feed for four hours to ensure that digesta was present in the digestive tract to perform gut viscosity measurements. The experimental period was a total of 21 days, and measured variables associated with performance included: D1 starting pen weight, D21 ending bird weight, pen FI, feed conversion ratio (FCR), bird live weight gain (LWG), and pen percent mortality.

\section{Digesta Viscosity Measurements}

On D21, three birds from each pen were euthanized via cervical dislocation. The entire digestive tract was removed, and the digesta was squeezed out by hand into a $50 \mathrm{~mL}$ centrifuge tube [24]. The digesta was centrifuged [25] at 12,700 RPM for 5 min at $4{ }^{\circ} \mathrm{C}$ [26]. A pipette was utilized to transport $1 \mathrm{~mL}$ of supernatant into a microcentrifuge tube. The microcentrifuge tube was placed in a $25^{\circ} \mathrm{C}$ water bath [27] for approximately $10 \mathrm{~min}$. After, $0.5 \mathrm{~mL}$ of supernatant 
was placed in a Brookfield Cone and Plate Viscometer [28] with a CPE-40 cone and a CPE-44Y cup. Measurements were taken at $30 \mathrm{sec}$ and $1 \mathrm{~min}$ at both speeds of 10 and 20 RPM. Similar methodologies were utilized by Lee and coauthors [29].

\section{Statistical Analysis}

A Dose X Processing and a Diet Formulation X Processing factorial arrangement of treatments was used to explore main effects and interactions of particular treatments on performance and gut viscosity. The factorial arrangement of treatments may be better appreciated by observing Table 2. In addition, an overall comparison was conducted on all 12 treatments using the Fisher's LSD multiple comparison test. In all analyses a randomized complete block design was utilized with one pen of 10 birds as the experimental unit. All data were analyzed using the GLM procedure of Statistical Analysis System [30]. Alpha was designated as 0.05 , and letter superscripts were used to denote differences among treatment means.

\section{RESULTS AND DISCUSSION}

\section{Feed Manufacture \& Enzyme Activity}

A cursory discussion of descriptive data may be useful when considering treatment affects (Table 2). The authors speculate that the PC diet had decreased descriptive $\mathrm{HPT}\left(76^{\circ} \mathrm{C}\right)$, PDI (55\%), and percent pellets (92\%) due to the high inclusion of fat that increased lubrication of the pellet die. Variation of formulated fat inclusion was the primary cause for PC and NC difference in energy content. Ground pelleted diets had a decreased descriptive bulk density and increased descriptive average percent moisture compared to the unprocessed mash diets. The particle size differences between the two feed forms were not remarkable. 
The descriptive enzyme activity data suggests that GA is more thermally stable compared to GB under the pelleting conditions of the current study (Figure 1).

\section{Live Bird Performance}

Glucanase A Dose and Processing. Treatments that included GA were affected by a Dose X Processing interaction for D21 ending bird weight $(\mathrm{P}=0.0465$, Table 3$)$, demonstrating that GA dosed at 1000 Units/kg of feed increased ending bird weight for birds fed ground pelleted diets but not unprocessed mash diets. The authors speculate that the pelleting process changes ingredient confirmation and improved the opportunity for gluc to interact with substrates. In addition, the main effect Processing was significant for D21 ending bird weight, pen FI, and bird LWG (P < 0.0001, Table 3 and 4), describing that birds fed ground pelleted diets had a higher ending weight, FI, and LWG compared to birds fed unprocessed mash diets. These results were also observed by Gracia and coauthors [31] where they found that heat processing of barley improved FI and LWG from D 0 to 8 in spite of the increase observed in intestinal viscosity. A Dose $\mathrm{X}$ Processing interaction was significant for DV measurements taken at 10 RPM for $30 \mathrm{sec}$ and $1 \mathrm{~min}(\mathrm{P}<0.05$, Table 3), demonstrating that GA dosed at $1000 \mathrm{Units} / \mathrm{kg}$ of feed decreased DV for birds fed ground pelleted diets. The main effect Processing was significant for DV measurements taken at $20 \mathrm{RPM}$ for $30 \mathrm{sec}$ and $1 \mathrm{~min}(\mathrm{P}<0.05$, Table 3$)$, describing that birds fed ground pelleted diets had a higher DV compared to birds fed unprocessed mash diets. Østergård and coauthors [32] discovered that heat processing increased the solubility of the fibrous portion of barley; and therefore, the digesta viscosity was also increased. These scientists also observed that heat processing modifies starch, protein, and fiber structure of the cereal; and consequently, improves accessibility of enzymes to nutrients, facilitating its digestibility [32]. The DV measurements of the current study are approximately 
$2.0 \mathrm{cP}$ less than DV measurements our laboratory has obtained in high viscous wheat diets that were detrimental to performance [33].

Diet Formulation and Processing. The main effect Diet Formulation was significant for D21 ending bird weight, bird LWG, and FCR ( $\mathrm{P}<0.05$, Table 4), describing that birds fed PC had a higher ending bird weight and LWG and a lower FCR compared to birds fed NC, GA 1000 Units $/ \mathrm{kg}$ of feed, and GB 1000 Units $/ \mathrm{kg}$ of feed diets. The main effect Diet Formulation was significant for pen FI ( $\mathrm{P}=0.0497$, Table 4), demonstrating that birds fed PC and GB 1000 Units/kg of feed had a higher FI compared to birds fed GA 1000 Units $/ \mathrm{kg}$ of feed. The main effect Diet Formulation was also significant DV measurements taken at 10 and 20 RPM for 30 $\sec (\mathrm{P}<0.05$, Table 4), demonstrating that birds fed NC and GA 1000 Units/kg of feed had a higher DV compared to birds fed GB 1000 Units/kg of feed. For DV measurements taken at 10 RPM for $1 \mathrm{~min}$, the main effect Diet Formulation was significant $(P=0.0069$, Table 4), describing that birds fed GB 1000 Units/kg of feed had a lower DV compared to birds fed NC, PC, and GA 1000 Units/kg of feed. The main effect Diet Formulation was significant for DV measurements taken at $20 \mathrm{RPM}$ for $1 \mathrm{~min}(\mathrm{P}=0.0014$, Table 4), describing that birds fed NC and GA 1000 Units/kg of feed had a higher DV compared to birds fed PC and GB 1000 Units/kg of feed.

Overall Comparison. For ground pellets, GA dosed at $1000 \mathrm{U} / \mathrm{kg}$ of feed was superior to $\mathrm{NC}$ and indistinguishable from PC for ending bird weight and LWG $(\mathrm{P}<0.0001$, Table 5). These benefits were not observed for GB, perhaps in due part to a 50\% decrease in enzyme activity post pelleting (Figure 1). Birds fed PC (unprocessed mash and ground pellets) obtained significantly decreased FCR compared to birds fed all other 10 treatments. Birds that consumed ground pelleted diets had greater pen FI compared to birds fed unprocessed mash diets ( $\mathrm{P}<$ 
0.0001, Table 5). For DV at 10 RPM at $30 \mathrm{sec}$ and $1 \mathrm{~min}$, NC ground pellet had the statistically highest DV and NC unprocessed mash, GA 125, 500, and $2000 \mathrm{U} / \mathrm{kg}$ of feed unprocessed mash, GB $1000 \mathrm{U} / \mathrm{kg}$ of feed, GA $1000 \mathrm{U} / \mathrm{kg}$ of feed, and PC had the lowest values $(\mathrm{P}<0.05$, Table 5). For DV at $20 \mathrm{RPM}$ at $30 \mathrm{sec}$ and $1 \mathrm{~min}, \mathrm{NC}$ ground pellet had the statistically highest DV and NC unprocessed mash, GA 125, 500, and 2000 U/kg of feed unprocessed mash, GB $1000 \mathrm{U} / \mathrm{kg}$ of feed, and PC had the lowest value $(\mathrm{P}<0.05$, Table 5).

\section{CONCLUSIONS AND APPLICATIONS}

1. Descriptive enzyme activity data suggests that GA is more thermally stable compared to GB when conditioned at $80^{\circ} \mathrm{C}$.

2. Treatments that included GA were affected by an interaction between Dose X Processing for ending bird weight and DV at 10 RPM $(\mathrm{P}<0.05)$. Birds fed GA dosed at 1000 Units/kg of feed decreased DV and increased weight gain for ground pelleted diets; however, these beneficial effects were not apparent for birds fed unprocessed mash diets.

3. The main effect Processing was significant $(\mathrm{P}<0.05)$ for pen FI, LWG, and DV at 20 RPM. Birds fed ground pelleted diets had a greater pen FI, LWG, and an increased DV versus mash diets.

4. For ground pellets, GA dosed at $1000 \mathrm{U} / \mathrm{kg}$ of feed was superior to $\mathrm{NC}$ and indistinguishable from PC for ending bird weight and LWG. These benefits were not observed for GB dosed at $1000 \mathrm{U} / \mathrm{kg}$ of feed, perhaps in part due to a $50 \%$ decrease in activity post pelleting. 


\section{REFERENCES AND NOTES}

1. Gohl, B., S. Aldén, K. Elwinger, and S. Thomke. 1978. Influence of $\beta$-glucanase on feeding value of barley for poultry and moisture content of excreta. British Poultry Science 19: 41-47.

2. Annison, G. and M. Choct. 1991. Anti-nutritive activities of cereal non-starch polysaccharides in broiler diets and strategies minimizing their effects. World's Poult. Sci. J. 47:232-242.

3. Jeroch, H. and S. Dänicke. 1995. Barley in poultry feeding: a review. World's Poultry Science Journal 51:271-291.

4. Fuente, J. M., P. Perez de Ayala, A. Flores, and M. J. Villamide. 1998. Effect of storage time and dietary enzyme on the metabolizable energy and digesta viscosity of barleybased diets in poultry. Poultry Science 77:90-97.

5. Chesson, A. 1993. Feed enzymes. Anim. Feed Sci. Technol. 45:65-69.

6. Bedford, M. R. 2000. Exogenous enzymes in monogastric nutrition - The current value and future benefits. Anim. Feed Sci. Technol. 86:1-13.

7. Hesselman, K. and P. Åman. 1986. The effect of $\beta$-glucanase on the utilization of starch and nitrogen by broiler chickens fed on barkey of low-or-high-viscosity. Animal Feed Science and Technology 15:83-93.

8. Annison, G. 1992. Commercial enzyme supplementation of wheat-based diets raises ileal glycanase activities and improves apparent metabolisable energy, starch and pentosan digestibilities in broiler chickens. Animal Feed Science and Technology 38:105-121.

9. Esteve-Garcia, E., J. Brufau, A. Pérez-Vendrell, A. Miquel, and K. Duven. Bioefficacy of enzyme preparations containing $\beta$ - glucanase and xylanase activities in broiler diets 
based on barley or wheat, in combination with flavomycin. 1997. Poultry Science 76:1728-1737.;

10. Silversides, F. G., and M. R. Bedford. 1999. Effect of pelleting temperature on the recovery and efficacy of a xylanase enzyme in wheat-based diets. Poultry Science 78:1184-1190.

11. Eeckhout, M., M. DeSchrijver, and E. Vanderbeke. 1995. The influence of process parameters on the stability of feed enzymes during steam pelleting. Pages 163-169 in: Proceedings of the $2^{\text {nd }}$ European Symposium on Feed Enzymes. Noordwijkerhout, The Netherlands.

12. Gehring, C. K., K. G. S. Lilly, L. K. Shires, K. R. Beaman, S. A. Loop, and J. S. Moritz. 2011. Increasing mixer-added fat reduces the electrical energy required for pelleting and improves exongenous enzyme efficacy for broilers. J. Appl. Poult. Res. 20:75-89.

13. Inborr, J., and M. R. Bedford. 1994. Stability of enzymes to steam pelleting during feed processing. Animal Feed Science and Technology 46:179-196.

14. Almirall, M. and E. Esteve-Garcia. 1995. In vitro stability of $\beta$-glucanase preparation from Trichoderma longibrachiatum and its effects in a barley based diet fed to broiler chicks. Animal Feed Science and Technology 54: 149-158.

15. Vertical mixer, Avery Weigh-Tronix, Fairmont, MN

16. 4.25-ft length, 1.02-ft diameter short-term California Pellet Mill conditioner (3 steam inlet ports), 429 rpm shaft speed, 21 picks, 10-s feed retention time, California Pellet Mill Company, Crawfordsville, IN

17. Master Model Pellet Mill, California Pellet Mill Company, Crawfordsville, IN. 18. Fluke 51 II, Everette, WA 
19. New Holmen NHP Portable Pellet Durability Tester, Lignotech USA, Inc., Rothschild, WI

20. Verenium Corporation; San Diego, CA.

21. Cosson, T., A. M. Pérez Vendrell, B. González Teresa, D. Reñé, P. Taillade, and J. Brufau. 1999. Enzymatic assays for xylanase and $\beta$-glucanase feed enzymes. Animal and Feed Science and Technology 77:345-353.

22. Cobb-Vantress, Siloam Springs, AR

23. Pilgrim's Pride, Moorefield, WV

24. Fisher Scientific, Fairlawn, NJ

25. Sorvall Evolution RC Centrifuge, Asheville, NC

26. Bedford, M. R. and H. L. Classen. 1992. Reduction of intestinal viscosity through manipulation of dietary rye and pentosanase concentration is effected through changes in the carbohydrate composition of the intestinal aqueous phase and results in improved growth rate and food conversion efficiency in broiler chicks. The Journal of Nutrition 122, no. $3: 560$

27. TC-602 Refrigerated Bath, Brookfield Engineering Laboratories Inc., Middleboro, MA

28. Brookfield LVDV-II+Pro Viscometer, Brookfield Engineering Laboratories Inc., Middleboro, MA.

29. Lee, J. T., C. A. Bailey, and A. L. Cartwright. 2003. Guar meal germ and hull fractions differently affect growth performance and intestinal viscosity of broiler chickens. Poultry Science 82:1589-1595.

30. SAS Institute. 2013. The SAS System for Windows 2013. Release 9.3. SAS Inst. Inc., Cary, NC. 
31. Gracia, M. I., M. A. Latorre, M. García, R. Lázaro, and G. G. Mateos. 2003. Heat processing of barley and enzyme supplementation of diets for broilers. Poultry Science $82: 1281-1291$.

32. Østergård, K., I. Björck, and J. Vainionpää. 1989. Effects of extrusion cooking on starch and dietary fiber in barley. Food Chemistry 34:215-227.

33. Lamp, A. E. 2012. West Virginia University, Morgantown, WV. Unpublished data.

\section{Acknowledgements}

The authors would like to acknowledge the West Virginia University farm staff, especially Rick Wood for technical support. 
Table 1. Diet formulations ${ }^{1}$ for the negative and positive control diets

\begin{tabular}{|c|c|c|}
\hline Item & $\begin{array}{c}\text { Negative control, \% } \\
\text { inclusion }\end{array}$ & $\begin{array}{c}\text { Positive control, \% } \\
\text { inclusion }\end{array}$ \\
\hline \multicolumn{3}{|l|}{ Ingredients } \\
\hline Barley & 45.00 & 40.00 \\
\hline Soybean meal & 26.05 & 23.87 \\
\hline Corn & 17.98 & 22.77 \\
\hline Soybean oil & 4.17 & 5.01 \\
\hline Porcine meat and bone meal & 3.00 & 5.00 \\
\hline Dicalcium phosphate & 1.45 & 1.26 \\
\hline Limestone & 0.87 & 0.65 \\
\hline Salt & 0.40 & 0.37 \\
\hline DL - methionine & 0.32 & 0.32 \\
\hline Lysine & 0.27 & 0.26 \\
\hline $\mathrm{NB}^{2} 3000^{2}$ & 0.25 & 0.25 \\
\hline Threonine & 0.11 & 0.11 \\
\hline Coban $90^{3}$ & 0.08 & 0.08 \\
\hline $\mathrm{BMD}^{4}$ & 0.05 & 0.05 \\
\hline \multicolumn{3}{|l|}{ Calculated nutrients } \\
\hline $\mathrm{ME}(\mathrm{kcal} / \mathrm{kg})$ & 2880 & 3030 \\
\hline Crude Protein $(\%)$ & 21.29 & 21.13 \\
\hline Lysine (\%) & 1.18 & 1.18 \\
\hline Available Phosphorus (\%) & 0.45 & 0.45 \\
\hline Calcium $(\%)$ & 0.91 & 0.91 \\
\hline
\end{tabular}

${ }^{1}$ Both the positive and negative control diets were formulated based on industry recommendations and digestible amino acid matrices and differed by $150 \mathrm{kcal} / \mathrm{kg}$.

${ }^{2}$ Vitamin-mineral premix (NB3000, Nutrablend, Neosho, MO) supplied the following per kilogram of diet: manganese, $0.02 \%$; zinc, $0.02 \%$; iron, $0.01 \%$; copper, $0.0025 \%$; iodine, $0.0003 \%$; selenium, $0.00003 \%$; folic acid, $0.69 \mathrm{mg}$; choline, $386 \mathrm{mg}$; riboflavin, $6.61 \mathrm{mg}$; biotin, $0.03 \mathrm{mg}$; vitamin $\mathrm{B}_{6}, 1.38 \mathrm{mg}$; niacin, $27.56 \mathrm{mg}$; pantothenic acid, $6.61 \mathrm{mg}$; thiamine, $2.20 \mathrm{mg}$; menadione, $0.83 \mathrm{mg}$; vitamin $\mathrm{B}_{12}, 0.01 \mathrm{mg}$; vitamin $\mathrm{E}, 16.53 \mathrm{IU}$; vitamin $\mathrm{D}_{3}$, 2,133 ICU; vitamin A, 7,716 IU.

${ }^{3}$ Active drug ingredient monensin sodium, $60 \mathrm{~g} / \mathrm{lb}$ (90 g/ton inclusion; Elanco Animal Health, Indianapolis, IN) as an aid in the prevention of coccidiosis caused by Eimeria necatrix, Eimeria tenella, Eimeria aceryulina, Eimeria brunette, Eimeria mivati, and Eimeria maxima.

${ }^{4}$ Bacitracin methylene disalicylate, $50 \mathrm{~g} / \mathrm{lb}$ (50 g/ton inclusion; Alpharma, Fort Lee, NJ), for increased rate of bird weight gain and improved feed efficiency. 
Table 2. Feed manufacture variables associated with variation in diet formulation (descriptive data)

\begin{tabular}{|c|c|c|c|c|c|c|c|c|c|c|c|}
\hline Feed Form & $\begin{array}{c}\text { Conditioning } \\
\text { Temperature } \\
\left({ }^{\circ} \mathrm{C}\right)\end{array}$ & $\operatorname{Trt}^{1}$ & $\begin{array}{c}\text { Dose }^{2} \\
\text { (Units/ } \\
\text { kg feed) }\end{array}$ & $\begin{array}{c}\text { Avg Hot } \\
\text { Pellet Temp } \\
\left({ }^{\circ} \mathrm{C}\right)\end{array}$ & $\begin{array}{c}\text { Production } \\
\text { Rate } \\
\text { (tonne/hr) } \\
\end{array}$ & $\begin{array}{c}\text { NHPT }^{3} \\
30 \text { sec } \\
(\%)\end{array}$ & $\begin{array}{l}\text { Percent } \\
\text { Pellets }^{4}\end{array}$ & $\begin{array}{c}\text { Bulk } \\
\text { Density } \\
\left(\mathrm{kg} / \mathbf{m}^{3}\right)\end{array}$ & $\begin{array}{c}\text { Avg. } \\
\text { Moisture }^{6} \\
(\%)\end{array}$ & $\begin{array}{c}\text { Particle } \\
\text { Size }^{7} \\
\text { (microns) } \\
\end{array}$ & $\begin{array}{l}\text { Standard } \\
\text { Deviation }\end{array}$ \\
\hline \multirow{5}{*}{$\begin{array}{l}\text { Ground } \\
\text { Pellet }\end{array}$} & \multirow{5}{*}{80} & \multirow{2}{*}{ GA } & 125 & 77.93 & 0.834 & 72.65 & 96.93 & 507 & 14.28 & 1086 & 1.80 \\
\hline & & & 1000 & 77.22 & 0.790 & 71.20 & 97.79 & 520 & 13.93 & 1051 & 1.82 \\
\hline & & GB & 1000 & 76.25 & 0.786 & 73.25 & 95.45 & 526 & 13.60 & 1104 & 1.78 \\
\hline & & $\mathrm{NC}$ & --- & 77.39 & 0.798 & 75.10 & 95.44 & 521 & 14.06 & 1082 & 1.76 \\
\hline & & $\mathrm{PC}$ & --- & 76.11 & 0.761 & 55.40 & 92.32 & 522 & 14.03 & 1094 & 1.79 \\
\hline & & & & & & & & & & & \\
\hline \multirow{7}{*}{$\begin{array}{c}\text { Unprocessed } \\
\text { Mash }\end{array}$} & \multirow{7}{*}{---} & \multirow{4}{*}{ GA } & 125 & --- & --- & --- & --- & 621 & 12.80 & 1080 & 1.93 \\
\hline & & & 500 & $\begin{array}{ll}--- \\
\end{array}$ & --- & --- & $\begin{array}{l}--- \\
\end{array}$ & 608 & 12.43 & 1085 & 1.96 \\
\hline & & & 1000 & --- & --- & --- & --- & 620 & 12.52 & 1022 & 1.96 \\
\hline & & & 2000 & --- & --- & --- & --- & 617 & 12.61 & 1073 & 1.95 \\
\hline & & GB & 1000 & $\begin{array}{ll}--- \\
\end{array}$ & --- & --- & $\begin{array}{l}--- \\
\end{array}$ & 616 & 12.46 & 1109 & 1.95 \\
\hline & & $\mathrm{NC}$ & --- & --- & $\begin{array}{ll}-- \\
\end{array}$ & --- & --- & 623 & 12.70 & 1090 & 1.93 \\
\hline & & $\mathrm{PC}$ & --- & --- & --- & --- & --- & 622 & 12.32 & 1109 & 1.99 \\
\hline
\end{tabular}

${ }^{1}$ Treatments: $\mathrm{PC}=$ positive control; $\mathrm{NC}=$ negative control (positive and negative control diets had an energy difference of $150 \mathrm{kcal} / \mathrm{kg}$ );

$\mathrm{GA}=$ glucanase $\mathrm{A} ; \mathrm{GB}=$ glucancase $\mathrm{B}$

${ }^{2}$ All enzymes were added to a $2.3 \mathrm{~kg}$ of NC diet, mixed, then added back to the larger NC batch, and mixed again.

${ }^{3}$ New Holmen Pellet Tester: Pellet durability index based on the New Holmen Pellet Tester that uses a sample of $100 \mathrm{~g}$ of pellets and air flow within a perforated chamber for $30 \mathrm{~s}$.

${ }_{5}^{4}$ Percent pellets were defined as the percentage of crumbles from a $2.3 \mathrm{~kg}$ feed sample that did not pass through a No. 6 screen.

5 Bulk Density data was obtained with a container of known volume.

${ }_{7}^{6}$ Average percent moisture data was obtained using AOAC dry matter methodology and duplicate samples.

${ }^{7}$ Particle size was determined with a Ro-Tap particle size analyzer model RX-29 type 110V 60H2, WS Tyler, Mentor, OH. One hundred grams of each ground pelleted diet was placed in a dust-tight enclosed series of stacked (No. 4, 6, . .) American Society for Testing and Materials (ASTM) screens affixed to the RoTap particle size analyzer and shaken for $10 \mathrm{~min}$. The screens were then separated and weighed. Particle size was calculated by subtracting the weight of the screen from the final weight of screen and sample after shaking. The mean geometric particle size and log normal geometric standard deviation were calculated as described by McEllhiney, 1994 
Figure 1. Target glucanase activity and DNS assay results

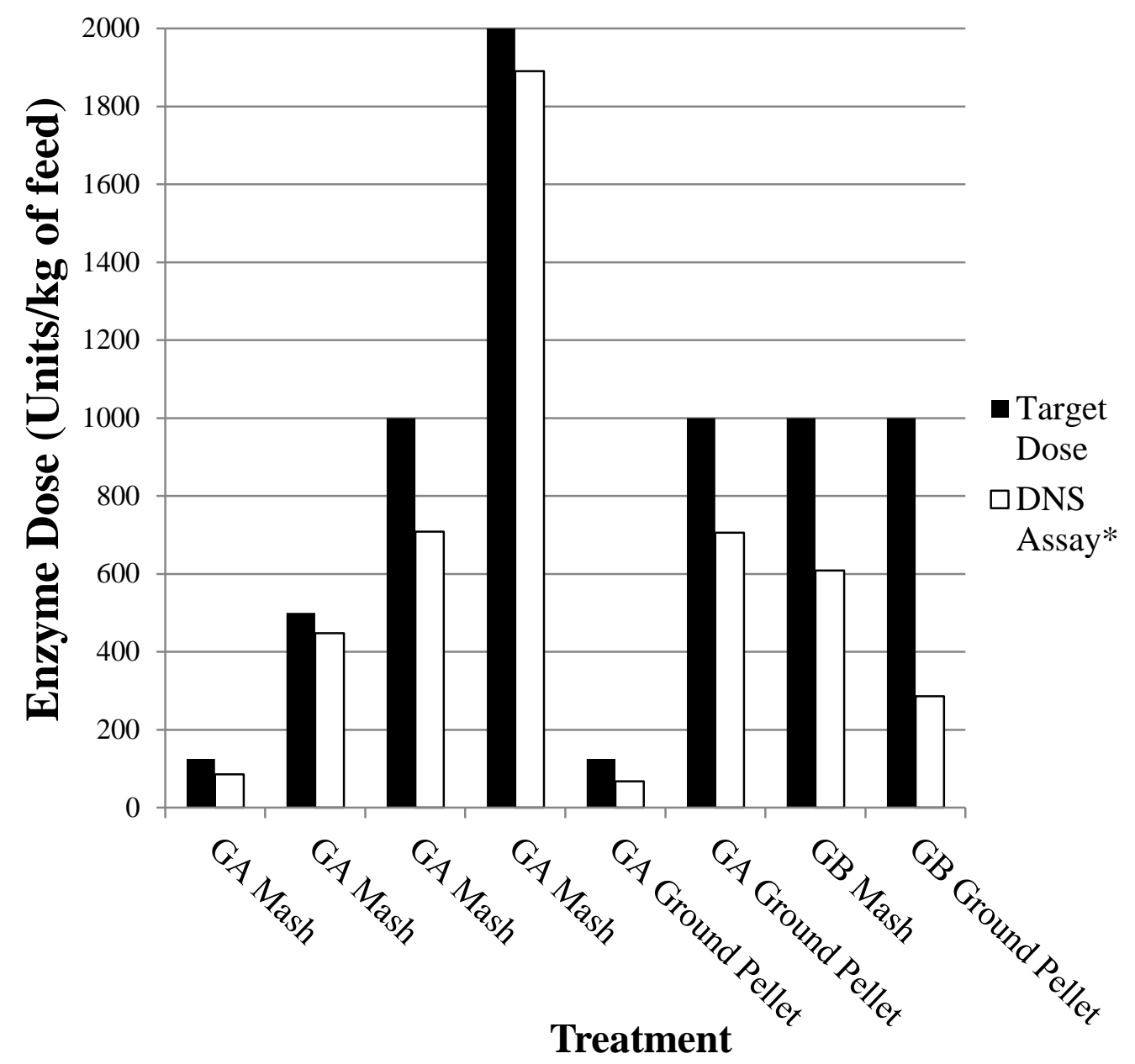

"Dinitrosalicyclic acid (DNS) assay: Cosson, T., A. M. Pérez Vendrell, B. González Teresa, D. Reñé, P. Taillade, and J. Brufau. 1999. Enzymatic assays for xylanase and $\beta$-glucanase feed enzymes. Animal and Feed Science and Technology 77:345-35 
Table 3. The effect of Glucanase A dose $(0,125,1000)$ and processing (unprocessed mash or ground pellet) on broiler performance and gut viscosity.

\begin{tabular}{|c|c|c|c|c|c|c|c|c|c|c|c|c|}
\hline \multirow{3}{*}{ Enzyme } & \multirow{3}{*}{$\begin{array}{c}\text { Dose } \\
\text { (Units/kg } \\
\text { feed) }\end{array}$} & \multirow{3}{*}{ Processing } & \multirow{3}{*}{$\begin{array}{c}\text { Day 1 } \\
\text { Starting } \\
\text { Pen } \\
\text { Weight }^{1} \\
(\mathbf{k g}) \\
\end{array}$} & \multirow{3}{*}{$\begin{array}{c}\text { Day } 21 \\
\text { Ending } \\
\text { Bird } \\
\text { Weight } \\
\text { (kg) }\end{array}$} & \multirow{3}{*}{$\begin{array}{c}\text { Pen Feed } \\
\text { Intake } \\
(\mathbf{k g})\end{array}$} & \multirow{3}{*}{$\begin{array}{c}\mathrm{FCR}^{3} \\
(\mathrm{~kg} / \mathrm{kg})\end{array}$} & \multirow{3}{*}{$\begin{array}{c}\text { Bird } \\
\text { LWG }^{2} \\
(\mathbf{k g})\end{array}$} & \multirow{3}{*}{$\begin{array}{c}\text { Pen } \\
\text { Percent } \\
\text { Mortalit } \\
\mathbf{y}^{4}(\%)\end{array}$} & \multicolumn{4}{|c|}{ Gut Viscosity (cP) } \\
\hline & & & & & & & & & \multicolumn{2}{|c|}{$\begin{array}{c}10 \mathrm{RPM} \\
\left(\mathrm{SR}^{5}=75 \mathrm{sec}^{-1}\right) \\
\end{array}$} & \multicolumn{2}{|c|}{$\begin{array}{c}20 \mathrm{RPM} \\
\left(\mathrm{SR}^{5}=150 \mathrm{sec}^{-1}\right)\end{array}$} \\
\hline & & & & & & & & & $30 \mathrm{sec}$ & $1 \mathrm{~min}$ & $30 \mathrm{sec}$ & $1 \mathrm{~min}$ \\
\hline \multicolumn{13}{|c|}{ Marginal Means } \\
\hline \multirow{5}{*}{$\begin{array}{c}\text { Glucanase } \\
\text { A }\end{array}$} & 0 & --- & 0.469 & 0.675 & 9.15 & 1.47 & 0.628 & 0.625 & 6.28 & 6.09 & 5.90 & 5.73 \\
\hline & 1000 & --- & 0.456 & 0.679 & 8.98 & 1.45 & 0.633 & 2.50 & 5.66 & 5.59 & 5.82 & 5.73 \\
\hline & & & & & & & & & & & & \\
\hline & --- & $\begin{array}{c}\text { Unprocessed } \\
\text { Mash }\end{array}$ & 0.467 & 0.647 & $8.66^{\mathrm{b}}$ & 1.46 & $0.600^{\mathrm{b}}$ & 1.25 & 5.29 & 5.23 & $5.26^{\mathrm{b}}$ & $5.14^{\mathrm{b}}$ \\
\hline & --- & $\begin{array}{c}\text { Ground } \\
\text { Pellet }\end{array}$ & 0.458 & 0.707 & $9.84^{\mathrm{a}}$ & 1.46 & $0.661^{\mathrm{a}}$ & 1.25 & 6.38 & 6.29 & $6.49^{\mathrm{a}}$ & $6.36^{\mathrm{a}}$ \\
\hline \multicolumn{3}{|c|}{ Processing } & 0.2906 & $<0.0001$ & $<0.0001$ & 0.9135 & $<0.0001$ & 1.0000 & 0.0360 & 0.0293 & 0.0106 & 0.0106 \\
\hline \multicolumn{3}{|c|}{ Dose X Processing } & 0.5435 & 0.0465 & 0.3787 & 0.5322 & 0.0729 & 0.1862 & 0.0163 & 0.0412 & 0.1525 & 0.1468 \\
\hline
\end{tabular}

${ }^{1}$ Starting pen weights were based on 10 birds per pen.

${ }^{2}$ Live Weight Gain.

${ }^{3}$ Feed Conversion Ratio (Feed:Gain) was calculated using mortality weight.

${ }^{4}$ Mortality percentage is based on 10 birds per pen, so if 2 birds died the mortality percentage would be $20 \%$ for that experimental unit/pen.

${ }^{5}$ Shear Rate. 
Table 4. The effect of diet formulation (NC, PC, Glucanase A 1000 U/kg feed, Glucanase B 1000 U/kg feed) and processing (unprocessed mash or ground pellet) on broiler performance and gut viscosity.

\begin{tabular}{|c|c|c|c|c|c|c|c|c|c|c|c|}
\hline \multirow{3}{*}{$\begin{array}{c}\text { Diet } \\
\text { Formulation }\end{array}$} & \multirow{3}{*}{ Processing } & \multirow{3}{*}{$\begin{array}{c}\text { Day } 1 \\
\text { Starting } \\
\text { Pen } \\
\text { Weight }^{1} \\
\text { (kg) }\end{array}$} & \multirow{3}{*}{$\begin{array}{c}\text { Day } 21 \\
\text { Ending } \\
\text { Bird } \\
\text { Weight } \\
\text { (kg) }\end{array}$} & \multirow{3}{*}{$\begin{array}{c}\text { Pen Feed } \\
\text { Intake } \\
(\mathbf{k g})\end{array}$} & \multirow{3}{*}{$\begin{array}{c}\mathrm{FCR}^{3} \\
(\mathrm{~kg} / \mathrm{kg})\end{array}$} & \multirow{3}{*}{$\begin{array}{c}\text { Bird } \\
\text { LWG }^{2} \\
(\mathbf{k g})\end{array}$} & \multirow{3}{*}{$\begin{array}{c}\text { Pen } \\
\text { Percent } \\
\text { Mortality } \\
(\%)\end{array}$} & \multicolumn{4}{|c|}{ Gut Viscosity (cP) } \\
\hline & & & & & & & & \multicolumn{2}{|c|}{$\begin{array}{c}10 \mathrm{RPM} \\
\left(\mathrm{SR}^{5}=75 \mathrm{sec}^{-1}\right) \\
\end{array}$} & \multicolumn{2}{|c|}{$\begin{array}{c}20 \text { RPM } \\
\left(\mathrm{SR}^{5}=150 \mathrm{sec}^{-1}\right)\end{array}$} \\
\hline & & & & & & & & 30 sec & 1 min & 30 sec & $1 \mathrm{~min}$ \\
\hline \multicolumn{12}{|c|}{ Marginal Means } \\
\hline Negative Control & --- & 0.469 & $0.675^{b}$ & $9.15^{\mathrm{ab}}$ & $1.47^{\mathrm{a}}$ & $0.628^{b}$ & 0.625 & $6.28^{\mathrm{a}}$ & $6.09^{\mathrm{a}}$ & $5.90^{\mathrm{a}}$ & $5.73^{\mathrm{a}}$ \\
\hline $\begin{array}{c}\text { Glucanase A } \\
1000 \mathrm{U} / \mathrm{kg} \text { feed }\end{array}$ & --- & 0.456 & $0.679^{b}$ & $8.98^{b}$ & $1.45^{\mathrm{a}}$ & $0.633^{b}$ & 2.50 & $5.66^{\mathrm{a}}$ & $5.59^{\mathrm{a}}$ & $5.82^{\mathrm{ab}}$ & $5.73^{\mathrm{a}}$ \\
\hline $\begin{array}{c}\text { Glucanase B } \\
1000 \mathrm{U} / \mathrm{kg} \text { feed }\end{array}$ & --- & 0.464 & $0.683^{b}$ & $9.29^{\mathrm{a}}$ & $1.47^{\mathrm{a}}$ & $0.637^{b}$ & 0.625 & $4.20^{\mathrm{b}}$ & $4.10^{b}$ & $4.14^{\mathrm{c}}$ & $4.08^{b}$ \\
\hline Positive Control & --- & 0.455 & $0.708^{\mathrm{a}}$ & $9.26^{\mathrm{a}}$ & $1.40^{\mathrm{b}}$ & $0.663^{\mathrm{a}}$ & 0.00 & $5.35^{\mathrm{ab}}$ & $5.28^{\mathrm{a}}$ & $4.85^{\mathrm{bc}}$ & $4.78^{b}$ \\
\hline--- & $\begin{array}{c}\text { Unprocessed } \\
\text { Mash } \\
\end{array}$ & 0.462 & $0.660^{\mathrm{b}}$ & $8.84^{b}$ & 1.45 & $0.614^{b}$ & 0.625 & 5.15 & 5.03 & 4.87 & 4.76 \\
\hline--- & $\begin{array}{l}\text { Ground } \\
\text { Pellet }\end{array}$ & 0.460 & $0.712^{\mathrm{a}}$ & $9.50^{\mathrm{a}}$ & 1.45 & $0.666^{\mathrm{a}}$ & 1.25 & 5.60 & 5.51 & 5.49 & 5.40 \\
\hline \multicolumn{12}{|c|}{ Main Effect and Interaction Probabilities } \\
\hline \multicolumn{2}{|c|}{ Diet Formulation } & 0.3810 & 0.0048 & 0.0497 & $<0.0001$ & 0.0041 & 0.0838 & 0.0075 & 0.0069 & 0.0012 & 0.0014 \\
\hline \multicolumn{2}{|c|}{ Processing } & 0.7192 & $<0.0001$ & $<0.0001$ & 0.7303 & $<0.0001$ & 0.3816 & 0.2776 & 0.2371 & 0.0757 & 0.0609 \\
\hline \multicolumn{2}{|c|}{ Diet Formulation X Processing } & 0.3929 & 0.0903 & 0.5927 & 0.3501 & 0.1195 & 0.2847 & 0.0677 & 0.1727 & 0.1565 & 0.1391 \\
\hline
\end{tabular}

${ }^{1}$ Starting pen weights were based on 10 birds per pen.

${ }^{2}$ Live Weight Gain.

${ }^{3}$ Feed Conversion Ratio (Feed:Gain) was calculated using mortality weight.

${ }^{4}$ Mortality percentage is based on 10 birds per pen, so if 2 birds died the mortality percentage would be $20 \%$ for that experimental unit/pen.

${ }^{5}$ Shear Rate 
Table 5. Overall comparison of all dietary treatments on broiler performance and gut viscosity.

\begin{tabular}{|c|c|c|c|c|c|c|c|c|c|c|c|c|}
\hline \multirow{3}{*}{ Treatment } & \multirow{3}{*}{$\begin{array}{c}\text { Dose } \\
\text { (Units/ } \\
\text { kg feed) }\end{array}$} & \multirow{3}{*}{ Processing } & \multirow{3}{*}{$\begin{array}{c}\text { Day 1 } \\
\text { Starting } \\
\text { Pen } \\
\text { Weight }^{1} \\
(\mathrm{~kg})\end{array}$} & \multirow{3}{*}{$\begin{array}{c}\text { Day } 21 \\
\text { Ending } \\
\text { Bird } \\
\text { Weight } \\
\text { (kg) }\end{array}$} & \multirow{3}{*}{$\begin{array}{c}\text { Pen } \\
\text { Feed } \\
\text { Intake } \\
\text { (kg) }\end{array}$} & \multirow{3}{*}{$\begin{array}{c}\mathbf{F C R}^{3} \\
(\mathbf{k g} / \mathbf{k g})\end{array}$} & \multirow{3}{*}{$\begin{array}{c}\text { Bird } \\
\text { LWG }^{2} \\
(\mathbf{k g})\end{array}$} & \multirow{3}{*}{$\begin{array}{c}\text { Pen } \\
\text { Percent } \\
\text { Mortality }^{4} \\
(\%)\end{array}$} & \multicolumn{4}{|c|}{ Gut Viscosity (cP) } \\
\hline & & & & & & & & & \multicolumn{2}{|c|}{$\begin{array}{c}10 \text { RPM } \\
\left(\mathrm{SR}^{6}=75 \mathrm{sec}^{-1}\right)\end{array}$} & \multicolumn{2}{|c|}{$\begin{array}{c}20 \text { RPM } \\
\left(\mathrm{SR}^{6}=150 \mathrm{sec}^{-1}\right)\end{array}$} \\
\hline & & & & & & & & & $30 \mathrm{sec}$ & $1 \mathrm{~min}$ & $30 \mathrm{sec}$ & $1 \mathrm{~min}$ \\
\hline $\begin{array}{l}\text { Negative } \\
\text { Control }\end{array}$ & --- & Unprocessed Mash & 0.479 & $0.657^{\mathrm{c}}$ & $8.78^{\text {cde }}$ & $1.46^{\mathrm{a}}$ & $0.609^{c}$ & 1.25 & $5.24^{\text {bcd }}$ & $5.18^{\mathrm{bcd}}$ & $4.93^{b c}$ & $4.76^{\mathrm{bc}}$ \\
\hline $\begin{array}{c}\text { Negative } \\
\text { Control }\end{array}$ & --- & Ground Pellet & 0.459 & $0.694^{b}$ & $9.52^{\mathrm{ab}}$ & $1.47^{\mathrm{a}}$ & $0.648^{\mathrm{b}}$ & 0.00 & $7.33^{\mathrm{a}}$ & $7.00^{\mathrm{a}}$ & $6.88^{\mathrm{a}}$ & $6.71^{\mathrm{a}}$ \\
\hline Glucanase A & 125 & Unprocessed Mash & 0.467 & $0.645^{\mathrm{c}}$ & $8.63^{\mathrm{e}}$ & $1.46^{\mathrm{a}}$ & $0.598^{\mathrm{c}}$ & 1.25 & $4.46^{\mathrm{cd}}$ & $4.56^{\mathrm{cd}}$ & $4.99^{\mathrm{bc}}$ & $4.90^{\mathrm{bc}}$ \\
\hline Glucanase A & 500 & Unprocessed Mash & 0.457 & $0.657^{\mathrm{c}}$ & $8.80^{\text {cde }}$ & $1.45^{\mathrm{a}}$ & $0.605^{\mathrm{c}}$ & 0.00 & $5.12^{\text {bcd }}$ & $5.04^{\text {bcd }}$ & $4.75^{\mathrm{bc}}$ & $4.65^{\mathrm{bc}}$ \\
\hline Glucanase A & 1000 & Unprocessed Mash & 0.454 & $0.639^{c}$ & $8.57^{\mathrm{e}}$ & $1.46^{\mathrm{a}}$ & $0.593^{\mathrm{c}}$ & 1.25 & $6.19^{\mathrm{abc}}$ & $5.93^{\mathrm{abc}}$ & $5.85^{\mathrm{ab}}$ & $5.77^{\mathrm{ab}}$ \\
\hline Glucanase A & 2000 & Unprocessed Mash & 0.457 & $0.646^{\mathrm{c}}$ & $8.72^{\text {de }}$ & $1.45^{\mathrm{a}}$ & $0.600^{\mathrm{c}}$ & 0.00 & $4.29^{\mathrm{d}}$ & $4.37^{\mathrm{cd}}$ & $4.87^{\mathrm{bc}}$ & $4.81^{b c}$ \\
\hline Glucanase B & 1000 & Unprocessed Mash & 0.458 & $0.656^{\mathrm{c}}$ & $9.04^{\mathrm{c}}$ & $1.48^{\mathrm{a}}$ & $0.611^{\mathrm{c}}$ & 0.00 & $3.83^{\mathrm{d}}$ & $3.77^{\mathrm{d}}$ & $4.11^{c}$ & $4.03^{c}$ \\
\hline Glucanase A & 125 & Ground Pellet & 0.457 & $0.709^{\mathrm{ab}}$ & $9.71^{\mathrm{a}}$ & $1.46^{\mathrm{a}}$ & $0.663^{\mathrm{ab}}$ & 0.00 & $6.69^{\mathrm{ab}}$ & $6.61^{\mathrm{ab}}$ & $6.81^{\mathrm{a}}$ & $6.67^{\mathrm{a}}$ \\
\hline Glucanase A & 1000 & Ground Pellet & 0.457 & $0.718^{\mathrm{a}}$ & $9.38^{\mathrm{b}}$ & $1.45^{\mathrm{a}}$ & $0.673^{\mathrm{a}}$ & 3.75 & $5.13^{\text {bcd }}$ & $5.25^{\mathrm{bcd}}$ & $5.79^{\mathrm{ab}}$ & $5.70^{\mathrm{ab}}$ \\
\hline Glucanase B & 1000 & Ground Pellet & 0.470 & $0.709^{\mathrm{ab}}$ & $9.54^{\mathrm{ab}}$ & $1.46^{\mathrm{a}}$ & $0.662^{\mathrm{ab}}$ & 1.25 & $4.57^{\mathrm{cd}}$ & $4.43^{\mathrm{cd}}$ & $4.16^{\mathrm{c}}$ & $4.13^{\mathrm{c}}$ \\
\hline Positive Control & --- & Unprocessed Mash & 0.458 & $0.690^{\mathrm{b}}$ & $8.96^{\mathrm{cd}}$ & $1.39^{\mathrm{b}}$ & $0.644^{\mathrm{b}}$ & 0.00 & $5.33^{\mathrm{bcd}}$ & $5.23^{\mathrm{bcd}}$ & $4.58^{\mathrm{bc}}$ & $4.50^{\mathrm{bc}}$ \\
\hline Positive Control & --- & Ground Pellet & 0.451 & $0.726^{\mathrm{a}}$ & $9.57^{\mathrm{ab}}$ & $1.41^{\mathrm{b}}$ & $0.681^{\mathrm{a}}$ & 0.00 & $5.37^{\mathrm{bcd}}$ & $5.34^{\text {bcd }}$ & $5.12^{\mathrm{bc}}$ & $5.06^{\mathrm{bc}}$ \\
\hline \multicolumn{3}{|c|}{ ANOVA P-value } & 0.6154 & $<0.0001$ & $<0.0001$ & $<0.0001$ & $<0.0001$ & 0.1247 & 0.0067 & 0.0063 & 0.0009 & 0.0006 \\
\hline \multicolumn{3}{|c|}{$\mathrm{SEM}^{5}$} & 0.009 & 0.009 & 0.112 & 0.013 & 0.009 & 0.898 & 0.626 & 0.574 & 0.502 & 0.478 \\
\hline
\end{tabular}

${ }^{1}$ Starting pen weights were based on 10 birds per pen.

${ }^{2}$ Live Weight Gain.

${ }^{3}$ Feed Conversion Ratio (Feed:Gain) was calculated using mortality weight.

${ }^{4}$ Mortality percentage is based on 10 birds per pen, so if 2 birds died the mortality percentage would be $20 \%$ for that experimental unit/pen.

${ }^{5}$ Standard Error of the Mean.

${ }^{6}$ Shear Rate. 


\section{Angela E. Lamp}

• 113 Laurel Circle ·Weirton, WV 26062 • alamp951@yahoo.com • (304) 9146061 •

Hard working and eager to expand knowledge. Excellent working as an individual, but also works well within a group.

Goal: To acquire animal husbandry and nutrition experience with exotic animals. To one day obtain a career in this field.

\section{EDUCATIONAL RECORD}
Master of Science - $\quad$ 2013; West Virginia University
Major: $\quad$ Nutrition and Food Science
Thesis: $\quad$ Improving Opportunities for Small Flock Poultry and Efficiency of Commercial Poultry

Bachelor of Science - 2012; West Virginia University

Major: $\quad$ Animal and Nutritional Sciences

\section{EDUCATION HONORS/AWARDS}

\section{Author Publications:}
Abstracts
A. E. Lamp, K. G. S. Lilly, B. N. Swiger, and J. S. Moritz. 2011 The effect of marine and flaxseed oil inclusion in diets for pastured laying flocks on EPA, DHA, and consumer acceptability of eggs. 2011 Poult. Sci. (Accepted Abstract).
A. E. Lamp, K. G. S. Lilly, B. N. Swiger, K. Matak, and J. S. Moritz. 2011 The effect of marine and flaxseed oil inclusion in diets for pastured laying flocks on EPA, DHA, and consumer acceptability of eggs. $18^{\text {th }}$ European Symposium on Poultry Nutrition. (Accepted Abstract \& Full Text Submission). Poster will be in Cesme- Izmir, Turkey. November 2011.
A. E. Lamp, M. E. Lemons, K. G. S. Wamsley, and J. S. Moritz. 2012 The effect of pasture access, breed, and diet on laying hen health, performance, and EPA and DHA content of eggs. 2012 Poult. Sci. (Accepted Abstract).
A.E. Lamp, A.M. Evans, and J.S Moritz. 2013. Feed manufacture technique affects heat transfer to feed that may influence nutritional value. 2013 International Southern Poultry Science Forum. Atlanta, GA. (Accepted Abstract). 
A.E. Lamp and J.S Moritz. 2013. The effect of pelleting and glucanase supplementation in barley based diets on feed manufacture, broiler performance, and gut viscosity. 2013 Poult. Sci. (Accepted Abstract).

\section{Co-Author Publications:}

\section{Abstracts}

M. E. Lemons, K. G. S. Wamsley, A. E. Lamp, A. M. Evans, K. J. Shipe, and J. S. Moritz. 2012. Lignosulfonate pellet binder and fat increase broiler feed retention time. 2012 Poult. Sci. (Accepted Abstract).

J.W. Boney, A.E. Lamp, and J.S Moritz. 2013. The effects of wheat supplementation to corn and soybean meal based diets on the manufacture of pellets and subsequent turkey performance. 2013 Poult. Sci. (Accepted Abstract).

\section{Graduate Awards and Honors:}

- Graduate Student Research Paper Certificate of Achievement, Feed manufacture technique affects heat transfer to feed that may influence nutritional value. 2013 International Southern Poultry Science Forum. Atlanta, GA. (Accepted Abstract).

- Graduate Student Research Paper Certificate of Excellence, The effect of pelleting and glucanase supplementation in barley based diets on feed manufacture, broiler performance, and gut viscosity. 2013 Poultry Science Association Meeting. San Diego, CA (Accepted Abstract).

Attended Marshall University

2008 - 2010

- A. Michael Perry Scholarship (2008-2010)

\section{Graduated from Weir High School in 2008:}

- Member of National Honor Society, Weir HS Chapter (2006-2008)

- Salutatorian

- All Conference Academic Award

- Who's Who Among Hugh School Students

- Student Council Treasurer

- USAA National English Award

\section{Scholarships Received:}

- Riverside Medical Scholarship (2008-2009)

- Aggarwal Family Scholarship (2008-2009)

- Kristen Andrews Scholarship (2008-2009)

- Stark Foundation Scholarship (2008-2009)

- West Virginia Promise Scholarship (2008-current) 


\section{RESEARCH EXPERIENCE}

\section{Graduate Research Assistant}

\section{Summer 2012 -Present}

- Led three contract studies with Verenium

- Led two contract studies with Virginia Poultry Grower's Coop

- Assisted with Contract Studies with Verenium and Lignotech

- Preston County Kid's Safety Day (6/9/2012 and 6/8/2013)

- Assisted with WV poultry week activities (7/26-7/27/2012)

- Poultry Judge for County Fairs (Berkeley County Youth Fair, WV; 8/7/2012) (Monongalia County, WV; 8/9/2012 and 8/1/2013)

- Assisted with Extension talks on backyard poultry production: Monongalia County (8/8/2012) and Gilmer County (10/18/2012)

- Guest Lecturer at Organic Poultry Field Day (8/9/2012)

- Assisted with running of the Poultry Building at the WV State Fair (8/15-8/16/2012)

- Assisted with Marion County Hands-on Ag Day (9/20/2012)

- Assisted with Poultry Career Development Events (9/26/2012 and 6/19/2013)

- Assisted with Family Day at the WVU Animal Science Farm (10/6/2012)

- Presented Poultry Judging lecture for Boy Scout's Animal Science Merit Badge $(2 / 9 / 2013)$

- Presented Feed Manufacture lecture for STEM program (8/7/2013)

- Assisted with Doddridge County Poultry Processing Workshop, WV (August, 2013)

\section{Graduate Teaching Assistant}

\section{Fall 2012 -Present}

- Teaching Assistant for Poultry Judging Course (ANPR 339)

- Guest Lecturer on Poultry Judging for Principles of Animal Science Class (A\&VS 251)

- Teaching Assistant for Companion Animal Science (A\&VS 275)

\section{National Meeting Paper Presentations}

- 2011 Poultry Science Association (St. Louis, MI) (Undergraduate Student)

"The effect of marine and flaxseed oil inclusion in diets for pastured laying flocks on EPA, DHA, and consumer acceptability of eggs."

- 2012 Poultry Science Association (Athens, GA) (Undergraduate Student)

"The effect of pasture access, breed, and diet on laying hen health, performance, and EPA and DHA content of eggs."

- 2013 Poultry Science Association (San Diego, CA) (Graduate Student)

"The effect of pelleting and glucanase supplementation in barley based diets on feed manufacture, broiler performance, and gut viscosity"

\section{National Meeting Poster Presentations}


- $201118^{\text {th }}$ European Symposium on Poultry Nutrition (Cesme- Izmir, Turkey) (Undergraduate Student)

"The effect of marine and flaxseed oil inclusion in diets for pastured laying flocks on EPA, DHA, and consumer acceptability of eggs."

- 2013 International Poultry Scientific Forum (Atlanta, GA) (Graduate Student)

"Feed manufacture technique affects heat transfer to feed that may influence nutritional value."

Undergraduate Research Assistant

Summer 2011-Summer 2012

- Led three ontract studies with Verenium

- Conducted study "Production of Omega-3 Fatty Acids Enhanced Eggs in a Pastured Poultry System"

- Assisted with Contract Studies with JBS United, Phytex, Verenium, Phytex, Poet Nutrition, Lignotech, and Adisseo

- Assisted with Poultry Workshop at WVU Organic Field Day (8/4/2011)

- Assisted with WV poultry week activities (Summer 2011)

- Assisted with activities and displays (birds and poster) for Monongalia County (Summer 2011)

- Assisted with two contract studies with Poet Nutrition Inc. utilizing various inclusions of dried distillers grains and soluble to establish sparing effects for lysine and available phosphorus (Summer 2011)

- Assisted with Extension talks on backyard poultry production: Doddridge County (2/20/2012), Roane County (2/21/2012), and Wood County (2/23/2012)

Undergraduate Teaching Assistant

Spring 2012

- Teaching Assistant for Poultry Judging Course (ANPR 338)

- Guest Lecturer on Poultry Judging for Principles of Animal Science Class (A\&VS 251)

\section{EXPERIENCE}

OIT Support Services

2010-2011

- Helped students print large posters

- Helped students with computer problems

Community Care Animal Hospital

2009

- Cleaned cages

- Assisted with animals

- Washed laundry

- Observed surgery

- Restrained animals

- Took x-rays

- Ran fecal floats

Kroger

- Pushed shopping carts from the parking lot into the store

- Bagged groceries for customers 
Hancock County Animal Shelter

- Cleaned cages

- Assisted with animals

- Washed laundry

Heilman Enterprises

2006-2007

- Completed construction projects

\section{SKILLS}

- Internet Literate

- Savvy in Window's Microsoft Programs

- Poultry Handling, Judging and Husbandry

- Feed Manufacture and Diet Formulation

- Precision-feeding

- Cecectomy Surgery

- Tibia Extraction

- Streak-plating for isolated colonies

- Experience with SAS

- Animal/Scientific specific courses taken:

- Animal Nutrition 260

- Animal Physiology 301

- Applied Nutrition 2362

- Intro to Biochemistry 410

- Environmental Microbiology 401

- Poultry Production 367

- Equine Management and Training 281

- Poultry Judging 338 \& 339

- Principles of Animal Science 251

- Companion Animal Science 275

- Comparative Vertebrate Anatomy 310

- Current Literature in Animal Science 451

- Graduate Courses

- Food Microbiology 545

- General Biochemistry 610

- Nutrition and Disease Prevention 614

- Statistics 511, 512

References available upon request 